\title{
Laser-based welding of 17-4 PH martensitic stainless steel in a tubular butt joint configuration with a built-in backing bar
}

\author{
Junjie Ma ${ }^{1}$, Mehdi Mazar Atabaki ${ }^{1}$, Wei Liu ${ }^{2}$, Raju Pillai ${ }^{2}$, Biju Kumar ${ }^{2}$, \\ Unnikrishnan Vasudevan ${ }^{2}$ and Radovan Kovacevic ${ }^{1, *}$ \\ ${ }^{1}$ Center for Laser-aided Manufacturing, Lyle School of Engineering, Southern \\ Methodist University, 3101 Dyer Street, Dallas, TX 75205 \\ ${ }^{2}$ National Oilwell Varco, Conroe, TX 77303
}

Abstract: Laser-based welding of thick 17-4 precipitation hardening (PH) martensitic stainless steel (SS) plates in a tubular butt joint configuration with a builtin backing bar is very challenging because the porosity and cracks are easily generated in the welds. The backing bar blocked the keyhole opening at the bottom surface through which the entrapped gas could escape, and the keyhole was unstable and collapsed overtime in a deep partially penetrated welding conditions resulting in the formation of pores easily. Moreover, the fast cooling rate prompted the ferrite transform to austenite which induced cracking. Two-pass welding procedure was developed to join 17-4 PH martensitic SS. The laser welding assisted by a filler wire, as the first pass, was used to weld the groove shoulder. The added filler wire could absorb a part of the laser beam energy; resulting in the decreased weld depth-to-width ratio and relieved intensive restraint at the weld root. A hybrid laser-arc welding or a gas metal arc welding (GMAW) was used to fill the groove as the second pass. Nitrogen was introduced to stabilize the keyhole and mitigate the porosity. Preheating was used to decrease the cooling rate and mitigate the cracking during laser-based welding of 17-4 PH martensitic SS plates.

Keywords: Laser welding assisted with a filler wire; hybrid laser-GMA welding; precipitation-hardening martensitic stainless steel; porosity mitigation; solidification cracking;

*To whom the correspondence should be addressed. Contact email address: kovacevi@lyle.smu.edu 


\section{Introduction}

The 17-4 PH martensitic SS combines good corrosion resistance, high strength and toughness, and good mechanical properties up to $316{ }^{\circ} \mathrm{C}$ [1]. The $17-4 \mathrm{PH}$ martensitic SS H1150 was produced by being heated up to $621{ }^{\circ} \mathrm{C}$ for 4 hour after the solution annealing, and its high strength is achieved by the presence of martensite at the room temperature in combination with precipitation hardening [1]. The material can be hardened by copper precipitation and $\mathrm{Fe}-\mathrm{Cr}$ spinodal decomposition achieved by annealing the material below $600{ }^{\circ} \mathrm{C}$ in the martensitic state $[2,3]$. Its microstructure consists of the tempered martensite and the recrystallized alpha ferrite that is formed in the martensite matrix during the overaged treatment [4]. The 17-4 precipitation hardening (PH) martensitic stainless steel (SS) is widely applied in aircraft components, pressure vessels, continuous extrusion equipment, chemical processing equipment, diaphragm assemblies, and tubular structures [5]. When welding the heavy wall tubular structures, a tubular butt joint configuration with a built-in backing bar has been normally used (Fig. 1) [6]. These types of joint are designed for the applications where a full weld penetration would affect the fluid flow inside the tubular structures.

Fig. 1. Schematic of the tubular butt joint configuration with a built-in backing bar The weldability of 17-4 PH martensitic SS is good for the traditional arc welding processes, such as gas tungsten arc welding (GTAW) [7], and shielded metal arc welding (SMAW) [8]. It is reported that welding of thick 17-4 PH martensitic SS plates is typically done in an overaged condition in order to reduce the crack susceptibility [9]. Das et al. [10] studied the GTA welding of $12 \mathrm{~mm}$ thick 17-4 PH SS plates in a single bevel groove configuration where the overaging was done at $621{ }^{\circ} \mathrm{C}$. Bhaduri et al. [11] reported that the $25 \mathrm{~mm}$ thick $17-4 \mathrm{PH}$ SS plates could be 
welded by GTAW and SMAW in a double-V configuration without post-weld heat treatment. Due to the good weldability for the traditional arc welding of 17-4 PH martensitic SS, preheating was reported as unnecessary [12].

Laser beam welding characterized as a high power density joining process possessed several advantages over traditional arc welding such as its high welding speed, deep penetration, and narrow heat affected zone (HAZ) [13]; however, laser beam welding of thick 17-4 PH martensitic SS plates in a tubular butt joint configuration with a built-in backing bar is very challenging because the porosity and cracks are easily generated in the welds. The backing would block the keyhole opening at the bottom surface making laser beam welding a deep partially penetrated welding process. It is difficult to maintain a stable keyhole all the time in the deep partially penetrated laser welding, pores are generated when the keyhole collapses [14]. Kaplan et al. [15] showed that the keyhole instability directly contributed to the porosity formation in deep penetration laser welding of steels. Dowden [16] found that the alteration in the molten pool fluid and the keyhole contributed to the keyhole collapse resulting in the formation of porosity. Dadras et al. [17] reported that the shielding gas or metal vapor could be trapped into the keyhole resulting in the porosity generation in the root of the keyhole during laser welding. The fast solidification of the molten pool trapes the gases generated during the laser welding resulting in the formation of porosity [13, 18]. Norris et al. [19] studied the keyhole stability and porosity formation in a partially penetrated laser welding of $304 \mathrm{~L}$ stainless steel. Due to the rapid solidification during the laser welding, the microstructure and composition in the weld zone were altered, where the generated austenite was susceptible to cracking [20, 21]. Shankar et al. [22] reported that the solidification cracking of the austenitic stainless welds could be associated with the elemental segregation [22]. Das et al. [10] studied 
the weldability of $17-4 \mathrm{PH}$ martensite SS in a $621{ }^{\circ} \mathrm{C}$ overaged condition, and they found that a primary ferritic solidification mode occurred when the ratio between $\mathrm{Cr}_{\mathrm{eq}}$ and $\mathrm{Ni}_{\mathrm{eq}}$ is higher than 1.5. Ziewiec et al. [23] studied the cracking mechanism of the welded joints of 17-4 PH martensitic SS precipitation hardened with copper, and they concluded that the cracks were generated near the fusion zone (FZ) side of the HAZ due to the steel embrittlement in the presence of $\mathrm{Cu}$ rich liquid phase.

In this study, a $10 \mathrm{~kW}$ disk laser, a gas metal arc welding (GMAW) power source, and a filler wire feeding system were used to conduct the laser-based welding (laser filler welding and hybrid laser-GMA welding) of the 17-4 PH martensitic SS plates. A high-speed charge-coupled device (CCD) camera combined with a green laser as the illumination source was employed to monitor the molten pool and plasma plume dynamics in real time. A spectrometer was used to detect the optical spectra emitted from the generated plasma during the laser-based welding processes. The volume and mass of the joint were calculated and the welding parameters were optimized according to the groove geometry. The effects of the welding parameters on the pore formation mechanism were studied. The microstructural evolution and solidification modes were discussed, and the laser-based welding procedures were optimized to mitigate the cracking during welding of 17-4 PH martensitic SS plates.

\section{Experimental procedure}

The base metal used in this study was 17-4 PH martensitic SS H1150 which has the density of $7820 \mathrm{~kg} / \mathrm{m}^{3}$, the yield strength of $1034 \mathrm{MPa}$, ultimate tensile strength of $1103 \mathrm{MPa}$, and the elongation of $11.0 \%$ [2]. The filler wire used for this study was ER630. The ER630 filler wire possesses the yield strength of $930 \mathrm{MPa}$ and the tensile strength of $1034 \mathrm{MPa}$ [24]. The chemical compositions of the 17-4 PH martensitic SS and filler wire ER 630 are shown in Table 1 [9]. 
Table 1 Chemical composition of 17-4 PH martensitic SS and ER 630 filler wire, wt\% [9]

The setup for the laser-based welding process for welding of 17-4 PH martensitic SS is shown in Fig. 2a. A 6-axis high-precision KUKA robot was used as a positioning system. A TRUMPF disk laser with a maximum power of $10 \mathrm{~kW}$ with a continuous wavelength of $1064 \mathrm{~nm}$ was used in this study. The laser was delivered by an optical fiber with a core diameter of $300 \mu \mathrm{m}$ to the laser head which has a $300 \mathrm{~mm}$ focal length. A GMAW power source (CLOOS Quinto GLC 403) was used for the arc welding, and a monitoring of the arc welding process was performed by Software Versions Management (SVM). A high precision filler wire feeding system (ABICOR BINZEL) was used. A programmable induction heater (Miller ProHeat 35) was used to preheat the coupons before welding (Fig. 2b). The power unit provided the high frequency current which passed through the induction coil generating a magnet filed which will heat the sample. Thermocouples were used to measure the temperature during the induction heating in order to ensure that a preheating temperature will not pass $300{ }^{\circ} \mathrm{C}$. The stainless steel samples were machined by a computer numerical control (CNC) milling machine to make different groove geometries with the variation in the groove angle and the shoulder height. In order to protect the molten pool from the atmosphere, argon as well as nitrogen were used as shielding gases during the welding. The specimens were fixed into the clamping fixture for the welding process.

Fig. 3 shows the schematic setup of the laser welding assisted with a filler wire and hybrid laser-GMA welding. The filler wire torch was tilted relative to the vertical axis for a $45^{\circ}$ angle, and the laser head was tilted $3^{\circ}$ relative to the vertical axis, resulting into the total angle between the filler wire torch and the laser head of $42^{\circ}$ (Fig. 3a). 
The GMAW torch was tilted relative to the vertical axis for a $20^{\circ}$ angle, resulting into the total angle between the GMAW torch and the laser head of $23^{\circ}$ (Fig. 3b).

Fig. 2. Setup for the (a) laser-based welding and (b) induction heating system

Fig. 3. Schematic setups for the (a) laser welding assisted with a filler wire and (b) hybrid laser-GMA welding

The positioning of the laser beam with respect to the arc plays an important role in hybrid laser-GMA welding of the thick stainless steel plates, because the synergy between laser and arc will be directly affected by the distance between the wire tip and laser beam spot at the sample surface. Based on the previous study on hybrid laser-GMA welding, the optimum value was chosen to be $2 \mathrm{~mm}$ in order to achieve the best synergy reaction between the laser and the arc [9]. For the laser welding assisted with a filler wire, laser beam was focused on the filler wire tip. The welding parameters were as follows: the laser power was between 9 and $9.9 \mathrm{~kW}$, welding speed was between 10 and $20 \mathrm{~mm} / \mathrm{s}$, wire feed rate was between 120 and $200 \mathrm{~mm} / \mathrm{s}$, arc current was between 225 and 290 A, the flow rate of shield gas (argon or nitrogen) was set at 991 liters per hour (LPH).

Since the $25.4 \mathrm{~mm}$ thick stainless steel need to be welded in one pass or two passes, the welding procedure that assured a penetration all the way to the backing bar as well as that mitigated the porosity and cracking was selected for the further study.

Fig. 4 shows the schematic of the on-line monitoring system of the welding process which consists of a high-speed CCD camera and a spectrometer. A high-speed CCD camera with a maximum frame rate of 4000 frame per second (fps) was employed to monitor the plasma plume and the molten pool dynamic in real time. When the molten pool was monitored, a green laser with a band pass filter with a wavelength of $532 \mathrm{~nm}$ was used as an external illumination source. The Ocean Optics spectrometer (SD2000) 
was used to detect the optical spectra emitted from the generated plasma during the laser welding, GMA welding, and hybrid laser-GMA welding processes. The collimator lens of the spectrometer was positioned at $350 \mathrm{~mm}$ above the coupons and inclined $45^{\circ}$ angle with respect to the coupon surface. The integration time was $3 \mathrm{~ms}$, the wavelength resolution was $0.364 \mathrm{~nm}$, and the slit width was $50 \mu \mathrm{m}$. The temperature history on the coupon surface was measured by k-type thermocouples and the National-Instruments data acquisition system was used to acquire and record the corresponding temperature data during the welding process.

Fig. 4. Schematic of the on-line monitoring system with a high-speed CCD camera and a spectrometer

The scanning electron microscopy (SEM) was performed by LEO 1450VPSE. The microstructure of the welds was investigated by the Keyence VHX-1000 digital microscope. An abrasive water-jet machine (Integrated Flying Bridge Water-jet 4400, Flow International) was used to cut the coupons for observing the cross-sections of the weld beads. The cross-sectioned weld beads were polished and etched following the standard procedure for metallographic studies. A $5 \mathrm{~g} \mathrm{FeCl}_{3}+25 \mathrm{~mL} \mathrm{HCL}+10$ $\mathrm{mL} \mathrm{H}_{2} \mathrm{O}$ etching solution was used to reveal the weld microstructure.

The Vicker's micro-hardness measurement was carried out in order to determine the hardness distribution profiles along the weld zone and HAZ. The indenter load used in the micro-hardness test was 500 gram-force (gf) with the dwell time of $15 \mathrm{~s}$. The microhardness measurement was performed for an increment of $0.25 \mathrm{~mm}$ counted from the weld centerline until the microhardness reached the value of the base metal. There were various factors (e.g., laser power, robot scanning speed, shielding gas composition, shielding gas nozzle position, shielding gas flow rate, arc power density, sample thickness and groove geometry, stand-off distance between the arc and laser, 
filler wire tip position) affecting the results of welding of 17-4 $\mathrm{PH}$ martensitic SS plates. The effect of the parameters such as stand-off distance between the arc and laser, and the filler wire position were optimized and reported in the author's previous work $[25,26]$, and were directly used in this study. The most important welding parameters such as groove geometry, laser heat input, and wire feed rate were the points of interest in the present study. The hybrid laser-GMA welding and laser welding assisted with a filler wire process were very sensitive to the groove angle, shoulder height, and the pre-set gap of the coupons. The influence of geometrical parameters on the final weld quality was studied. The groove angle $(\theta)$ was varied from $10^{\circ}$ to $15^{\circ}$. The shoulder height was set between 9.5 and $12.7 \mathrm{~mm}$. The crosssection area, volume, and mass of the joint were calculated. Fig. 5 shows the schematic cross-section of the tubular butt joint configuration with a built-in backing bar. The dimension of the sample at the left side was $127 \mathrm{~mm}$ in length, $76.2 \mathrm{~mm}$ in width, and $25.4 \mathrm{~mm}$ in thickness; the dimension of the sample in right side was 127 $\mathrm{mm}$ in length, $76.2 \mathrm{~mm}$ in width, and $19.05 \mathrm{~mm}$ in thickness. Fig. 6 shows the schematic of the area of the joint cross-section, where $L$ is the thickness of the right plate, $H$ is the shoulder height, $\theta$ is the groove angle, $G$ is the gap size, and $h$ is the height of the weld reinforcement.

Fig. 5. Schematic cross-section of the tubular butt joint configuration with a built-in backing bar

Fig. 6. The schematic view of the area of the joint cross-section As discussed preciously, the groove angle $(\theta)$ was set in a small angle range from $10^{\circ}$ to $15^{\circ}$. Therefore, the vertical shadowed area $\left(\mathrm{A}_{\mathrm{cs}}\right)$ could be assumed as a circular sector with an angle of $2 \cdot \theta$. The horizontal shadowed area $\left(\mathrm{A}_{\text {gap }}\right)$ represents the gap area, and $\mathrm{A}_{\mathrm{ol}}$ is the overlapped area of $\mathrm{A}_{\mathrm{cs}}$ and $\mathrm{A}_{\mathrm{gap}}$; therefore, the area of the whole joint cross-section (A) could be calculated by using the following equations [1-4]: 
$A_{c S}=\frac{2 \cdot \theta}{360} \cdot \pi \cdot\left(L-H+\frac{G}{2 \cdot \tan \theta}+h\right)^{2}$

$A_{\text {gap }}=H \cdot G$

$A_{o l}=\frac{1}{2} \cdot G \cdot \frac{G}{2 \tan \theta}$

$A=A_{c s}+A_{g a p}-A_{o l}$

The deposited mass of the filler material could be calculated based on the area of the whole joint cross-section and the length of the weld.

The heat input $(Q)$ is the sum of the heat inputs of the laser $\left(Q_{L}\right)$ and the GMAW $\left(Q_{G}\right)$ for the laser-GMA welding and was calculated by using Equation 5. The energy transfer efficiencies for laser and GMA welding of stainless steel were set at $0.72\left(\eta_{L}\right)$ [27], and $0.8\left(\eta_{G}\right)$ [28], respectively. $P$ is the laser power, $U$ and $I$ are the voltage and current of the GMAW, and $v$ is the scanning speed. The total heat input can be calculated as:

$Q=\eta_{L} \cdot Q_{L}+\eta_{G} \cdot Q_{G}=\eta_{L} \cdot P / v+\eta_{G} \cdot(U \cdot I) / v$

\section{Experimental Results and Discussion}

\subsection{Optimization of welding parameters}

Two-pass welding procedure was selected for the further study in order to ensure a penetration all the way to the backing bar as well as to mitigate the porosity and cracking. The laser welding assisted by a filler wire was used to weld the groove shoulder as the first pass; a hybrid laser-arc welding or a GMA welding was used to fill the groove as the second pass. Six approaches and the corresponding results are listed in Table 2. The experiments were designed in order to study the effect of the groove angle, shoulder height, the gap size, the filler material volume, and the heat input on the weld quality. The weld configurations and the corresponding weld crosssections are shown in Fig. 7. 
Table 2 Order of experimental trials with corresponding results

Fig. 7. The weld configurations and the weld cross-sections corresponding to Table 2

A small shoulder height could allow the laser beam easier to achieve a weld penetrated into the backing bar; however, a smaller shoulder height resulted in a larger groove which requires larger volume of the filler material which is related to an extra heat input. In order to achieve the smaller shoulder height with the decreased volume of the filler material, a $10^{\circ}$ groove angle was used. The laser beam was set to be focused at the shoulder, which was also the bottom of the groove, and the molten material was accumulated above the shoulder due to a very narrow groove geometry. However, the molten material would defocused the laser beam resulting in the keyhole collapse, and the presence of porosity in the weld should be expected (Fig. 7a). Therefore, it was suggested to use a larger shoulder height that will lead to a larger groove angle. A pre-set gap enhanced the downward fluid flow in the molten pool; thus, ensuring penetration of the laser beam all the way to the backing bar. The laser beam penetration was limited without a gap (Figs. 7b, and d); otherwise, the large gap caused the insufficient melting of the shoulder (Fig. 7c).

It is reported that the incident laser beam intensity could be affected by many absorptions in the groove. The number of the reflections $\left(n_{r}\right)$ into the keyhole and groove could be described by Equation (6) [29]:

$n_{r}=\left(\frac{\pi}{4 \cdot \theta_{w}}\right)$

where $\theta_{w}$ is the mean groove angle of the reflection. Mazar Atabaki et al. [29] reported that the increase in the groove angle caused the reduction in the intensity of the reflected light from the groove wall leading to its less absorption inside the groove. They developed the relationship between the number of reflections $\left(n_{r}\right)$, corresponding absorption coefficient, and the groove angle shown in Fig. 8. 
Fig. 8. The relationship among number of reflections $\left(n_{r}\right)$, corresponding absorption coefficient, and the groove angle [29].

If the shape and the angle of the groove were not optimized, the laser energy could not be uniformly absorbed which will result in the instability of the welding process. If the groove angle was too small, the molten material will accumulate above the shoulder and defocus the laser beam resulting in the keyhole collapse. In contrast, a large groove requires excessive volume of the filler material with an extra heat input resulting in a large HAZ with decreased mechanical properties of the joint. Within the optimum geometry of the groove both the laser beam and arc were stable and the synergic effect between them could be maintained all the time during the welding. Optimized groove geometry allowed enough weld penetration all the way to the backing bar and a sufficient fusion of the joint area, however, the defects such as porosity and cracks still were presented in the welds (Figs. 7e and f).

\subsection{Online monitoring the stability of the plasma plume during the laser-based welding processes}

The stability of the plasma plume generated during the optimal welding process was studied. The laser-induced plasma plume always maintained same shape and tilting angle indicates that the laser welding process was stable (Fig. 9a). The stable plasma plume indicates that the GMA welding and hybrid laser-GMA welding processes were stable as shown in Figs. 9b and c. Due to the synergic effect, the hybrid laserGMA welding possessed a larger molten pool and thicker plasma plume (Fig. 9c). The hybrid laser-GMA welding process had much larger plasma emission spectrum intensities compared with laser welding process (Fig. 10).

Fig. 9. The high-speed CCD camera captured images about the plasmas plume generated during the (a) laser welding, (b) GMA welding, and (c) hybrid laser-GMA welding of 17-4 PH martensitic SS 
Fig. 10. The plasma emission spectrum intensities captured by spectrometer generated during the (a) laser welding and (b) hybrid laser-GMA welding

The stability of the laser-induced plasmas plume under different shielding gas conditions was studied. Laser scanning in a bead-on-plates configuration was performed, where the laser power was set at $9.9 \mathrm{~kW}$, welding speed was set at 10 $\mathrm{mm} / \mathrm{s}$, and argon and nitrogen were chosen as the shielding gases respectively. The dynamic behavior of the plasma plume was observed by a high speed CCD camera. When nitrogen was chosen as shielding gas, the laser-induced plasma plume was always maintained the same plume angle and shape which indicated a stable welding process (Fig. 11a). When argon was chosen as shielding gas, the shape and plume angle of the laser-induced plasma plume was fluctuating at different time which indicated the welding process was unstable (Fig. 11b). Moreover, the argon plasma was much thicker than the nitrogen plasma. It was reported that the shielding gas with lower thermal conductivity, higher molecular weight, and lower ionization potential generated more plasma $[9,30]$. When argon was used as shielding gas, the metallic and argon plasma were continuously formed above the keyhole and became thicker. The thick plasma plume absorbed, defocused, and reflected the laser beam, and the interaction between laser and plasma caused both of the plasma and keyhole to become unstable. The intense evaporation in the bottom of the keyhole will be trapped by the collapsed keyhole forming bubbles. The intensities of the spectrum obtained from the laser-induced plasma plume is much more stable when using nitrogen as shielding gas than in the case of using argon (Fig. 12) This also verified that nitrogen could contribute to a stable welding process, under which condition the stable keyhole could be maintained to mitigate the porosity. 
Fig. 11. The plasma and plume captured by a high-speed CCD camera under different shielding gases

Fig. 12. The spectrum intensities captured by spectrometer during laser welding under different shielding gases

\subsection{Pore formation and its mitigation methods}

The built-in backing bar, used for the backing of the tubular butt joint, blocked the opening of the keyhole at the bottom surface during the welding process making it a deep partially penetrated welding process. It is reported that the porosity could be effectively prevented when changing from partial to full penetration. The reason for this was in the fact that in the fully penetrated weld an extra route at the bottom of weld pool would be opened for any entrapped gases to escape, which was also aided by the intensive fluid flow at the bottom of the weld pool [31]. This effect was absent in the partially penetrated welding resulting in the generation of the porosity in the weld. Moreover, during the laser-based welding process, pores may also form due to various influence factors, such as the instability of the keyhole, fluctuation of the molten pool, entrapment of the gases, the microstructure of the material, and the alloying elements. In the hybrid laser-GMA welding, when the off-set distance of the laser and arc was set improperly, the generated plasma may reflect as the laser making change in the laser heat input, which fails to keep the keyhole open all the time. In the laser welding assisted with filler wire, when the laser and wire positions were not set properly, the irradiation of the laser into the feeding wire blocked the stability of keyhole. The martensitic phase evolution in the weld zone may also influence the pores formation by driving them to the tip of the dendritic structure in the FZ [29]. The pores also could be generated when the solidification rate was faster than the refilling rate of the molten material into a void caused by the collapsed keyhole. The shielding gas, which is used to protect the molten pool, may be entrapped in it 
resulting in the porosity. Some of the pores presented in the weld bead may also be caused by the exposure of the molten pool surface to the atmosphere $[32,33]$.

During the welding process, the pores could be formed in the molten pool when the criterial pressure value satisfied the relationships between pressure and surface energy defined by Equation 7 [29]:

$$
P_{g}=P_{0}+\rho_{L} \cdot g_{r} \cdot h+\frac{2 \cdot \sigma_{g L}}{r}
$$

where $P_{g}$ is the threshold pressure for forming a pore, $P_{0}$ is the ambient air pressure, $\rho_{L} \cdot g_{r} \cdot h$ is the growth of hydrostatic pressure, $\sigma_{g L}$ is the surface energy of the pore, and $r$ is the radius of the pore.

The diffusion of a gas in the liquid metal could be defined as [29]:

$$
\frac{\partial C_{g}}{\partial t}+\left(\frac{R}{r}\right)^{2} \cdot \frac{d R}{d t} \cdot \frac{\partial C_{g}}{\partial r}=D \cdot \frac{\partial^{2} C_{g}}{\partial r^{2}}+\frac{2}{r} \cdot D \cdot \frac{\partial C_{g}}{\partial r}
$$

where $C_{g}$ is the gas concentration, $t$ is the time, $R$ is the bubble radius, $r$ is the spherical radial coordinate, and $D$ is the diffusivity of the gas into the SS. This Equation shows how the welding time influence the concentration of the gas, and a higher welding speed may contribute to a less concentration of gas inside the weld area [29]. The gas inside the bubble should follow the ideal gas law (Equation 9).

$$
P_{g} \cdot V_{g}=n_{g} \cdot R \cdot T_{W}
$$

where $P_{g}$ is the total gas pressure, $V_{g}$ is the volume, $T_{W}$ is the temperature in the welding pool and $n_{g}$ is the number of the gas moles.

During the laser welding process, the transition from the metastable to the stable state of the molten pool resulted in either the gas vent through molten pool or trapped to form pores [34]. The pores could be formed when the molten pool solidified too fast, and the void caused by the collapsed keyhole cannot be filled by the molten material. There are various influencing factors that will affect the stability of the keyhole and 
causing its collapse. It is reported that the collapse of keyhole could be influenced by the value of the aspect ratio between the keyhole depth to its width [35]. Norris et al. also found that the uniform pores were typically formed in the FZ under a higher welding speed in the laser welding and lower heat input; whereas, some pores were formed in the root part of the keyhole under a relatively lower welding speed and higher heat input [19].

During the welding process, it is assumed that an ideal gas is thermodynamically composed of many randomly moving gas elements, and they do not interact except when they collide elastically. Based on the assumption that the pores were generated by ideal gas, the relationship between the viscosity and the local temperature in the molten pool can be derived through the Sutherland's formula [36].

$\mu=\mu_{0} \cdot \frac{T_{0}+C}{T+C} \cdot\left(\frac{T}{T_{0}}\right)^{\frac{3}{2}}$

where $\mu$ is the dynamic viscosity in $\mathrm{kg} /(\mathrm{m} \cdot \mathrm{s})$ at the molten pool temperature, $T_{0}$ is the room temperature, $\mu_{0}$ is the reference viscosity in $\mathrm{kg} /(\mathrm{m} \cdot \mathrm{s})$ at the reference temperature, $T$ is the welding temperature affected by the heat input and $C$ is the Sutherland's constant depending on the type of ideal gas. This Equation could also be transformed to Equation 11.

$\mu=\lambda \cdot \frac{T^{3 / 2}}{T+C}$

where, $\lambda=\mu_{0} \cdot \frac{T_{0}+C}{T_{0}^{3 / 2}}$, and it could be considered as a constant for the gas, and the viscosity of the molten material dependent on the temperature of the molten pool, decided by the weld pool temperature window (varies from the melting point to the boiling point of the welded metal) indicates that by changing the heat input (combination of the laser based welding parameters) the viscosity of the molten material can varied up to fifty times more than its lowest value. The viscosity of the 
molten material affected by the heat input would influence the formation of the pores. When the heat input was increased, the viscosity of the molten material allowed the formed pores to move upward to the molten pool surface, and the molten material could fill the pores properly [29]. It was also reported that the alteration in the viscosity of the molten material and the molten pool fluid flow could contribute to the fluctuation and even collapse of the keyhole resulting in the formation of the porosity $[15]$

When the laser beam energy was not uniformly absorbed in the keyhole during the welding of 17-4 PH martensitic SS process, the evaporation intensity could be altered by the strong plasma; therefore, affect the stability of the welding process. It was reported that any variation in the keyhole dynamics and its instability could lead to the formation of the bubbles that may consist of $\mathrm{CO}$, argon, or vapor of the low-boiling point metals in the weld pool [19]. One reason for the formation of the pores was the entrapment of generated $\mathrm{CO}$ in the solidified molten pool. A good shielding condition was required in the laser based welding of 17-4 PH martensitic SS process. When the shielding condition became unstable, the contaminant gases may affect the molten pool. The $\mathrm{CO}$ might be generated due to the interaction between the oxygen from the atmosphere and carbon from the weld metal. The interaction of the elemental composition, and the equilibrium between liquid iron and oxygen dissolved in the liquid iron and liquid iron oxide could be described by Equations 12 and 13:

$C+O=C O$

$\mathrm{C}+\mathrm{FeO}=\mathrm{CO}+\mathrm{Fe}$

When the heat input was not in optimal range, the non-uniform vaporization of the low-boiling point metals occurred on the front wall of the keyhole affecting the stability of the keyhole, resulting into the trap of metal vapor into the collapsed 
keyhole forming the pores inside the molten pool during its solidification [37]. It is worth to note that, the inert shielding gas such as argon may also be trapped into the keyhole resulting in porosity due to the keyhole collapse in the welding process [38]. Fig. 13 shows different kind of pores presented in the longitudinal cross-section of the weld bead caused by various possible factors. The pores induced by the shielding gases are in a relatively smaller size (Fig. 13a). When the keyhole was collapsed, the low boiling point metal vapor or $\mathrm{CO}$ generated in the keyhole was trapped in the weld pool. The pores had relatively larger size and located along the bottom part of the weld bead (Fig. 13b). These types of pores were more dominant, demonstrating the possibility of entrapment of different gases in the molten pool.

Fig. 13. Different kind of pores presented in the longitudinal cross-sections of the SS welds.

The effects of welding speed on the porosity formation in hybrid laser-arc welding of 17-4 PH martensitic SS plates were studied. Three cases were compared under various welding speeds of $5 \mathrm{~mm} / \mathrm{s}, 10 \mathrm{~mm} / \mathrm{s}$, and $30 \mathrm{~mm} / \mathrm{s}$. The laser power was 9.9 $\mathrm{kW}$, arc current was $235 \mathrm{~A}$, and argon was used as the shielding gas with a flow rate of 991 liters per hour (LPH). The welds were cut along the weld center line along the longitudinal direction to illustrate the level of porosity and its distribution. As shown in Fig. 14a, pores were observed in the longitudinal weld cross-section which was obtained under a welding speed of $5 \mathrm{~mm} / \mathrm{s}$, and the pores were distributed along two lines located at the upper and lower part of the weld. Under a welding speed of 10 $\mathrm{mm} / \mathrm{s}$, the pores were only presented at the lower part of the longitudinal weld crosssection (Fig. 14b). When the welding speed was increased to $30 \mathrm{~mm} / \mathrm{s}$, pores were not observed along the longitudinal weld cross-section; however, cracks were presented in the weld (Fig. 14c). 
Fig. 14. Longitudinal cross-sectional view of the weld obtained under various welding speed of (a) $5 \mathrm{~mm} / \mathrm{s}$, (b) $10 \mathrm{~mm} / \mathrm{s}$, and (c) $30 \mathrm{~mm} / \mathrm{s}$ with a laser power of $9.9 \mathrm{~kW}$, arc current of $235 \mathrm{~A}$, argon was used as shielding gas with a flow rate of $991 \mathrm{LPH}$

Katayama et al. [39] studied the keyhole behavior, and bubble and porosity formation mechanisms under various welding speeds in the laser welding process. They reported that the bubbles were generated from the tip of the keyhole due to the evaporation of the keyhole front wall or keyhole collapse. There existed fast melt flows inside the molten pool, and the melt flow and bubble float were attributed to the evaporation of the keyhole front or keyhole collapse, not because of the buoyancy. At low welding speed, the evaporation at the keyhole front induced vapor bubble (together with shielding gas) into the molten pool and formed bubbles. When the keyhole collapsed, a laser beam was shot on the poured liquid, induced strong and large scale molten liquid flow. Therefore, some pores were formed at the keyhole tip which presents in the lower part of the weld, while some pores were formed at the tail of the molten pool which were presented in the upper part of the weld (Fig. 15a). At a medium welding speed, the flow near the bottom was weak, and the porosity was present near the bottom due to the collapsed keyhole (Fig. 15b). When the welding speed set at high level, the metal vapors vent upwards through the keyhole. This behavior induced melt flow opposite to the case of low welding speed and prevented invasion of shielding gas, which could effectively reduce the formation of the porosity (Fig. 15c).

Fig. 15. Schematic view of the effects of fluid flows on bubbles formation during laser welding at various speeds: (a) low welding speed, (b) medium welding speed, and (c) high welding speed [39].

Therefore, porosity could be mitigated in a higher welding speed, however, higher welding speed resulted in high cooling rate which induced cracking. Moreover, the penetration was limited under higher welding speed. Therefore, other approach should be taken to mitigate the porosity under relatively low welding speed. 
Unlike the traditional arc welding methods such as GTAW or SMAW, argon used as shielding gas could result in severe porosity for the hybrid laser-arc welded 17-4 PH martensitic SS joint [40]. Katayama et al. [41] studied the nitrogen as shielding gas in the laser welding, and found the nitrogen could greatly suppress the porosity formation due to a stable keyhole that was maintained during the welding. As shown in Fig. 16, with respect to the argon, the nitrogen could effectively mitigate the porosity under a welding speed of $10 \mathrm{~mm} / \mathrm{s}$. No pore and crack were observed in the longitudinal cross-section of the weld. It was reported that using nitrogen to replace argon as a shielding gas could increase the ductility of welded joint due to the fact that nitrogen could balance the ferrite-austenite phases in the weld metal. This is because nitrogen is austenite stabilizer and directly affects the reformation of austenite which could resulted in the structure with approximately equal amount of ferrite and austenite [42].

Fig. 16. Longitudinal cross-section of the weld obtained under shielding gas of (a) argon and (b) nitrogen with a laser power of $9.9 \mathrm{~kW}$, welding speed of $10 \mathrm{~mm} / \mathrm{s}$, arc current of $235 \mathrm{~A}$, shielding gas flow rate of $991 \mathrm{LPH}$

\subsection{Cracks formation and their mitigation methods}

Solidification cracks were very easily generated in the laser-based welding of 17-4 PH martensitic SS joints (Fig. 7). In the weld, the solidification cracks are the most deleterious and more presented than the other type of cracks. The generation of solidification cracking is overriding caused by the segregation of solutes to form low melting phases under the action of contraction stresses in the final stage of solidification [22].

Under equilibrium conditions, the initial solidifying phase is determined by the position of the alloy with respect to the liquidus surface [22]. For the welding process, the solidification condition is usually non-equilibrium, and segregation alters the 
product phases and their compositions. The material composition was considered as one of the main factors to determine its solidification behavior. The effect of solidification kinetics on the phases formed is very critical for the solidification in the welding. For stainless steel that is widely used in industry application usually contains around $70 \mathrm{wt} . \%$ iron, and its solidifying phases or solidification modes are normally considered as austenitic (A), austenitic-ferritic (AF), ferritic-austenitic (FA) and ferritic (F) [43]. Based on the pseudobinary diagram of the martensitic PH stainless steel in the arc welding process [8], the microstructural evolution during cooling is show in Fig. 17 [9]. At the beginning of the solidification phase when the temperature below $1480{ }^{\circ} \mathrm{C}$, the $17-4$ PH SS solidified as a prime ferrite. During cooling phase, the ferrite started to transform into austenite at the temperature of $1250{ }^{\circ} \mathrm{C}$. A large amount of austenite was transformed due to the solid-state diffusion [44]. At the martensitic transformation temperature ranging $\left(132\right.$ to $\left.32{ }^{\circ} \mathrm{C}\right)$, most of the austenite transformed into martensite. Some residual ferrite was also presented in the martensite matrix.

Fig. 17. Sequence of phase transformation for the PH martensitic SS cooling [9] It is reported that the generation of delta ferrite could be beneficial to prevent the solidification cracking in the welding of austenitic stainless steel [9]. Generally, the material was more prone to solidification cracking when the primarily solidification phase was austenite than ferrite, and a fully austenitic stainless steel weld is more prone to cracking than one containing ferrite $[21,22]$. The ferrite is also beneficial for its ability to contain some impurities within the grains, in order to avoid forming low melting point segregates and the consequently interdendritic cracks.

Segregation of impurities into the weld also induced cracking. Concentration of impurities could form a liquid film of low melting point in sequence producing 
segregates during solidification. As solidification proceeds, cracks were prone to be generated as the stresses were built up through normal thermal contraction. Therefore, welding with contaminants on the sample surface will introduce the impurities in the weld pool causing the cracking. It was also reported that the cracking was prone to occur under a higher restraint intensity of joint $[45,46]$.

The ratio of the chromium equivalent to the nickel equivalent $\left(\mathrm{Cr}_{\mathrm{eq}} / \mathrm{Ni}_{\mathrm{eq}}\right)$ was used to predict the solidification mechanism of the PH martensitic SS. Equations 14 and 15 are used to calculate $\mathrm{Cr}_{\mathrm{eq}}$ and $\mathrm{Ni}_{\mathrm{eq}}[47]$ :

$\mathrm{Cr}_{\mathrm{eq}}=\mathrm{Cr}+\mathrm{Mo}+0.7 \mathrm{Nb}$

$\mathrm{Ni}_{\mathrm{eq}}=\mathrm{Ni}+35 \mathrm{C}+20 \mathrm{~N}+0.25 \mathrm{Cu}$

For the base material 17-4 PH SS and the ER630 filler wire used in this study, the $\mathrm{Cr}_{\mathrm{eq}} / \mathrm{Ni}_{\mathrm{eq}}$ ratio is calculate as 2.8 and 2.5 , respectively [9]. It is reported that a ferritic solidification mode to the weld metal was a primary one in the gas tungsten arc welding of the material with $\mathrm{Cr}_{\mathrm{eq}} / \mathrm{Ni}_{\mathrm{eq}}$ ratio higher than 1.5 [9]. However, the cooling rate also affects the critical $\mathrm{Cr}_{\mathrm{eq}} / \mathrm{Ni}_{\mathrm{eq}}$ ratio. For the high speed laser welding, the fast cooling rate noticeably increases the critical $\mathrm{Cr}_{\mathrm{eq}} / \mathrm{Ni}_{\mathrm{eq}}$ ratio [48]. Since there is a limited information on the $\mathrm{Cr}_{\mathrm{eq}} / \mathrm{Ni}_{\mathrm{eq}}$ method for a high-speed laser welding, it is not accurate to determine the solidification behavior of the 17-4 PH SS based on the $\mathrm{Cr}_{\mathrm{eq}} / \mathrm{Ni}_{\mathrm{eq}}$ ratio.

It is reported that the base material composition is more important in high dilution situations such as welding the root in a butt joint configuration by using an autogenous welding technique like TIG, or submerged arc welding [49]. According to the European Standard EN 1011-2:2001, the possibility to generate crack in the submerged arc weld could be evaluated by the Units of Crack Susceptibility (UCS) from the weld metal chemical composition (weight \%): 
$\mathrm{UCS}=230 \mathrm{C}^{*}+190 \mathrm{~S}+75 \mathrm{P}+45 \mathrm{Nb}-12.3 \mathrm{Si}-5.4 \mathrm{Mn}-1$

$\mathrm{C}^{*}=$ carbon content less than $0.08 \%$ will be considered as equal to $0.08 \%$

If the UCS is less than 10 indicates the low cracking susceptibility, whereas UCS larger than 10 indicates a high toward cracking. According to the European Standard EN 1011-2:2001, when the UCS is in the range between 10 and 30, the risk of cracking will be increased greatly in a high depth-to-width ratio weld condition. There is relationship between the critical value of the depth-to-width ratio and the UCS value. When this ratio is about 1 , the UCS values of 20 and above will indicate a risk of cracking for the fillet welding, whereas the values of about 25 UCS are critical for the butt welding. When this ratio is around 0.8 , the UCS value could increase about nine. It is also needed to point out that when the full penetration is not achieved, the cracking is also prone to be generated.

As discussed in section 4.3, the pores were mitigated by choosing the nitrogen as shielding gas as well as the optimized welding parameters, the pore induced cracks could be also effectively avoided.

Fig. 18 shows the 17-4 PH martensitic SS weld cross-section acquired by the hybrid laser-GMA welding. The solidification cracks were presented in the lower part of the weld. The corresponding microstructure of the upper and lower part of the weld are shown in Fig. 19.

In the hybrid laser-GMA welding, the arc heat source provided a relatively low energy density compared to the laser beam which allowed a slow cooling rate at the upper part of the weld. Ferrite and martensite were presented at the upper part of the weld acquired by hybrid laser-GMA welding (Fig. 19a). However, in the welding process that laser beam was considered as the dominate heat source, a very high cooling rate was achieved due to the very high energy density of the laser beam. 
Therefore, the austenitic solidification mode appeared [9]. The austenite was observed in the region surrounding the solidification cracking area located at the lower part of the weld acquired by the hybrid laser-GMA welding (Fig. 19b). As discussed previously, these solidification cracks were generated due to two main factors. The formation of the austenite during the austenitic solidification mode, and a very large depth-to-width ratio of the weld pool which resulted in a high contraction stress at the root of the weld due to the solidification shrinkage. The austenite and the austenitic solidification mode should be suppressed in order to prevent the solidification cracking in the laser-based welding process. As discussed previously, presence of nitrogen could balance ferrite-austenite phases in the weld metal, which could increase the ductility of welded joint by increasing the amount of ferrite phase, which should contribute to the crack resistance [42]. An induction heater was used in this study to reduce the cooling rate at the root of the weld; thus, decrease the high thermal gradient in the center of the lower part of the weld. The preheating temperature was set at $300{ }^{\circ} \mathrm{C}$ in order to mitigate the solidification cracking. The cross-section of the corresponding weld is shown in Fig. 20. Fig. 21 shows the optical micrographs of the microstructure of the weld acquired by the hybrid laser-GMA welding after the preheating at $300{ }^{\circ} \mathrm{C}$ was done. Ferrite was presented both in the upper and lower part of the weld, and cracking was mitigated, which is softer than the martensite and austenite phases. The ferrite is favorable for cracking propagation resistance. By comparing the upper and lower part of the weld, the amount of the ferrite at the lower part of the weld was less than that at the upper part of the weld. This indicates that the lower part was more sensitive to the generation of cracks that could be attributed to a lower preheating temperature, an increase amount of impurities in the weld, a higher restraint intensity applied on the sample, or to the presence of pores in the welds. 
Fig. 18. Weld was acquired by the hybrid laser-GMA welding without preheating

Fig. 19. Microstructure of the (a) upper part, and (b) lower part of the weld as shown in Fig. 19

Fig. 20. Weld was acquired by the hybrid laser-GMA welding under preheating temperature of $300{ }^{\circ} \mathrm{C}$

Fig. 21. Microstructure of the (a) upper part, and (b) lower part of the weld which was acquired under preheating temperature of $300^{\circ} \mathrm{C}$

\subsection{Optimization of the laser-based welding procedure}

As discussed previously, preheating the sample will promote more ferrite in the weld which could suppress the solidification cracking. However, the amount of the ferrite in the lower part of the weld was less than that of the upper part of the weld. This indicated that the lower part was more sensitive to generate cracks when the cooling rate during the welding was increased. A laser welding with a filler wire was used to weld the lower part of the coupon, as the added filler wire could absorb some part of the laser beam energy; thus, will change the heat source energy distribution. Therefore, laser filler wire welding for the lower part of the joint could decrease the depth-to-width ratio of the weld and relieve the intensive restraint at the root of the weld [9]. A procedure based on a two-pass laser-based welding was developed to weld the preheated 17-4 PH martensitic SS. The laser welding assisted with a filler wire, as the first pass, was used to weld the lower part of the joint and a hybrid laserGMA welding or a GMA welding was used to fill the groove as the second pass (Figs. $22 \mathrm{a}$ and $\mathrm{b})$. According to the heat input and the filler wire volume, the corresponding parameters are listed in Table 3.

Fig. 22. Schematic of the two-pass laser-based welding of 17-4 PH martensitic SS for (a) Procedure No. 1 and (b) Procedure No. 2

Table 3. The optimum laser-based welding parameter 
The welds obtained by different welding procedures with a $300{ }^{\circ} \mathrm{C}$ preheating are shown in Figs. 23a and b. Sound and full penetration welds were achieved under the optimized paremeters. There were no pores and cracks observed on the weld surface, in the longitudinal cross-scetion, and cross-section of the welds.

Fig. 23. The top, longitudinal, and cross-sectional views of the joints obtained by the two-pass laser-based welding of 17-4 PH martensitic SS for welds obtained by: (a) Procedure No. 1 and (b) Procedure No. 2

The micro-hardness distribution profile of the welded coupons were measured along the lines shown in Fig. 24 at the upper and lower parts of the weld cross-section. As it is shown in the Figs. 24a and b, the hardness in the FZ was higher than that in the HAZ and the base material. The upper and lower parts of the FZ had almost the same hardness value around $350 \mathrm{HV}$, which means the laser welding assitsted with the filler wire could lower the cooling rate promoting more ferrite and causing the hardness value to decrease.

Fig. 24. The micro-hardness distribution profiles at the cross-section of the laserbased welded of 17-4 PH martensitic SS for welds obtained by: (a) Procedure No. 1 and (b) Procedure No. 2

\section{Conclusions}

Two-pass laser-based welding (laser welding assisted with a filler wire and hybrid laser-GMA welding) approach was developed to join the 17-4 PH martensitic SS plates in a butt joint configuration with a backing bar at the bottom. The laserbased welding parameters were optimized in order to have a sound joint without any pores and cracks. The influence of the laser-based welding parameters on the formation of the pores, the solidification mode, and cracks generation were investigated. The best geometry of joint was with a groove of a $15^{\circ}$ angle, a shoulder height of $12.7 \mathrm{~mm}$, and a pre-set gap of $1.2 \mathrm{~mm}$. The pores were generated by the 
entrapment of the gases in the molten pool when the keyhole was collapsed during the welding. The on-line monitoring of the laser-based welding process showed that the molten pool and the laser-induced plasma were stable, allowing a stable keyhole to mitigate the pores during the welding. The porosity could be reduced when the welding speed increased from low to medium level. A higher welding speed could mitigate the pores effectively, however, it caused the cracks in the weld. Nitrogen was used as shielding gas that could stabilize the keyhole, and effectively mitigate the porosity. Due to the high power density of the laser welding, a rapid cooling rate at the lower part of the weld was presented causing the transformation of the ferrite into austenite that would result in solidification cracking. The laser welding assisted with the filler wire could decrease the cooling rate which promote the presence of more ferrite in the weld. Preheating the sample could also decrease the cooling rate and formation of the austenite. Preheating the specimen up to $300{ }^{\circ} \mathrm{C}$ could effectively prevent the solidification cracking due to the presence of sufficient delta ferrite in the weld. The FZ of the weld possessed the hardness value around $350 \mathrm{HV}$ which was higher than that of the HAZ and the base material.

\section{Acknowledgement}

The financial support by NSF's Grant No. IIP-1034652 is acknowledged. The authors would like to thank the research engineer, Andrew Socha, in the Research Center for Advanced Manufacturing (RCAM) for his help in the execution of experiments.

\section{References}

[1] http://www.aksteel.com/

[2] F. Christien, M.T.F. Telling, K.S. Knight, A comparison of dilatometry and in-situ neutron diffraction in tracking bulk phase transformations in a martensitic stainless steel, Mater. Charact. 82 (2013) 50-57 
[3] G.E. Bacon, Neutron diffraction, monographs on the physics and chemistry of materials, Clarendon Press, Oxford, 1975.

[4] Y.C. Lin, Y.T. Lin, S.C. Chen, Z.R. Liu, Role of retained ferrite on the thermal fatigue cracking resistance in martensitic stainless steel weldment, Mater. Sci. Eng. A 339 (2003) 133-135

[5] http://www.harrisproductsgroup.com/

[6] W.H. Minnick, Flux Cored Arc Welding Handbook, 3rd Edition, GoodheartWillcox, 2008.

[7] D.W. Deng, C.P. Zhang, R. Chen, H.F. Xia, Post-weld heat treatment influence on galvanic corrosion of GTAW of $17-4 \mathrm{PH}$ stainless steel in $3.5 \% \mathrm{NaCl}$, International Federation for Heat Treatment and Surface Engineering (20th Congress), Phys Procedia 50 (2013) 177-184

[8] J. C. Lippold and D. J. Kotecki, Welding metallurgy and weldability of stainless steel, New York, Wiley, 2005.

[9] W. Liu, J. Ma, M. Atabaki, R. Pillai, B. Kumar, U. Vasudevan, H. Sreshta, Radovan Kovacevic, Hybrid laser-arc welding of 17-4PH martensitic stainless steel, Lasers in Manufacturing and Materials Processing, 2 (2015) 74-90

[10] C.R. Das, H.C. Dey, G. Srinivasan, S.K. Albert, A.K. Bhaduri, A, Dasgupta, Weldability of 17-4 PH stainless steel in overaged heat treated condition, Sci. Technol. Weld. Joi. 11(5) (2006) 502-508

[11] A.K. Bhaduri, S. Sujith, G. Srinivasan, T.P.S. Gill, S.L. Mannan, Optimized postweld heat treatment procedures for 17-4 PH stainless steels, Weld. J. 74(5) (1995) $153 \mathrm{~s}-159 \mathrm{~s}$

[12] J.H. Wu, C.K. Lin, Influence of high temperature exposure on the mechanical behavior and microstructure of 17-4 PH stainless steel, J. Mater. Sci, 38(5) (2003) 965-971

[13] J. Ma, F. Kong, R. Kovacevic, Finite-element thermal analysis of laser welding of galvanized high-strength steel in a zero-gap lap joint configuration and its experimental verification, Mater. Design. 36 (2012) 348-358

[14] W. Liu, J. Ma, R. Kovacevic, Hybrid laser-arc welding of advanced high-strength steel, J. Mater. Process. Technol. 214(12) (2014) 2823-2833

[15] A.F.H. Kaplan, M. Mizutani, S. Katayama, A. Matsunawa, Unbounded keyhole collapse and bubble formation during pulsed laser interaction with liquid zinc, J. Phys. D: Appl. Phys. 35 (2002) 1218-1228

[16] J. Dowden, Interaction of the keyhole and weld pool in laser keyhole welding, J. Laser Appl. 4(14) (2002) 204-209 
[17] S. Dadras, M.J. Torkamanya, J. Sabbaghzadeha, Spectroscopic characterization of low-nickel copper welding with pulsed Nd: YAG laser, Opt. Laser. Eng. 46 (2008) 769-776

[18] X. Gong, T. Anderson, K. Chou, Review on powder-based electron beam additive manufacturing technology, Manuf. Rev. 1 (2014) 1-12

[19] J.T. Norris, C.V. Robino, D.A. Hirshfeld, M.J. Perricone, Effects of laser parameters on porosity formation: investigating millimeter scale continuous wave $\mathrm{Nd}$ : YAG laser welds, Weld. J. 90 (2011) 198-203

[20] V. Kujanpää, N. Suutala, T. Takalo T. Moisio, Correlation between solidification cracking and microstructure in austenitic and austenitic-ferritic stainless steel, Weld. Res. Int. 9(2) (1979) 55-76s

[21] F.C. Hull, Delta ferrite and martnesite formation in stainless steels, Weld. J. 52(5) (1973) 193-203s

[22] V. Shankar, T.P.S. Gill, S.L. Mannan, S. Sundaresan, Solidification cracking in austenitic stainless steel welds, SADHANA 28 (3-4) (2003) 359-382

[23] A. Ziewiec, E. Tasak, J. Czech, Cracking of welded joints of the 17-4PH stainless martensitic steel precipitation hardened with copper, Arch. Metall. Mater. 57(4) (2012) 1055-1061

[24] http://www.techalloy.com/

[25] F. Kong, J. Ma, R. Kovacevic, Numerical and experimental study of thermally induced residual stress in the hybrid laser-GMA welding process, J. Mater. Process. Technol. 211(6) (2011) 1102-1111

[26] W. Liu, S. Liu, J. Ma, R. Kovacevic, Real-time monitoring of the laser hot-wire welding process, Opt. Laser. Technol. 57 (2014) 66-76

[27] A.P. Tadamalle, Y.P. Reddy, E. Ramjee, R. Vijayakumar, Evaluation of Nd: YAG laser welding efficiencies for 304L stainless steel, Procedia Materials Science, 6 (2014) 1731-1739

[28] J.N. Dupont, A.R. Marder, Thermal efficiency of arc welding processes, Welding J. 74 (1995) 406s-416s

[29] M.M. Atabaki, J. Ma, W. Liu, R. Kovacevic, Pore formation and its mitigation during hybrid laser/arc welding of advanced high strength steel, Mater. Design. 67 (2015) 509-521

[30] U. Reisgen, M. Schleser, O. Mokrov, E. Ahmed, Shielding gas influences on laser weldability of tailored blanks of advanced automotive steels, Appl. Surf. Sci. 257(5) (2010) 1401-1406 
[31] B. Chang, C. Allen, J. Blackburn, P. Hilton, Thermal and fluid flow characteristics and their relationships with porosity in laser welding of AA5083, Phys. Procedia. 41 (2013) $478-487$

[32] N. Seto, S. Katayama, A. Matsunawa, High-speed simulations observation of plasma and keyhole behavior during high power $\mathrm{CO} 2$ laser welding-effect of shielding gas on porosity formation, Proc ICALEO (1999) 19-27

[33] C.C. Hsiao, P.S. Wei, S.Y. Hsiao, Bubble entrapped in solid during solidification, In: Trends in welding research, proceedings of the 8th international conference, (2009) 190-193

[34] A.F.H. Kaplan, M. Mizutani, S. Katayama, A. Matsunawa. Mechanism of pore formation during keyhole laser spot welding, In: First international Symposium on High-Power Laser Macroprocessing (SPIE), 4831 (2003) 1-6

[35] J. Zhou, H. Tsai, Porosity formation and prevention in pulsed laser welding, J. Heat. Transfer. 129(8) (2006) 1014-1024

[36] J.C. Sutherland, C.A. Kennedy, Improved boundary conditions for viscous, reacting, compressible flows. J. Comput. Phys. 191(2) (2003) 502-24

[37] W. Meng, Z. Li, F. Lu, Y. Wu, J. Chen, S. Katayama, Porosity formation mechanism and its prevention in laser lap welding for T-joint, J. Mater. Sci. Technol. 214 (8) (2014)1658-1664s

[48] P. Berger, H. Hugel, T. Graf, Understanding pore formation in laser beam welding, Phys. Procedia. 12 (2011) 241-247

[39] S. Katayama, M. Mizutani, A. Matsunawa, Development of porosity prevention procedures during laser welding, In: First international Symposium on High-Power Laser Macroprocessing (SPIE), 4831 (2003) 281

[40] J. Nowacki, Weldability of 17-4 PH stainless steel in centrifugal compressor impeller applications, J. Mater. Process. Technol. 157 (2004) 578-583

[41] N. Seto, S. Katayama, A. Matsunawa, High-speed simultaneous observation of plasma and keyhole behavior during high power $\mathrm{CO} 2$ laser welding: effect of shielding gas on porosity formation, J. Laser Appl. 12(6) (2000) 245-250

[42] A. El-Batahgy, A. Khourshid, T. Sharef, Effect of laser beam welding parameters on microstructure and properties of duplex stainless steel, Mater. Sci. Appl. 2(10) (2011) 1443-1451

[43] S. Kou, Welding Metallurgy, 2nd Edition, Wiley, November 2002.

[44] J.A. Brooks, W.M. Garrison, Weld microstructure development and properties of precipitation strengthened martensitic stainless steels. Weld. J. 78 (1999) 280-s 
[45] S. Ohshita, N. Yurioka, N. Mori, T. Kimura, Prevention of solidification cracking in very low carbon steel welds, Weld. J. 62 (1983) 129s-136s

[46] X. Gong, J. Lydon, K. Cooper, K. Chou, Microstructure Analysis and Nanoindentation Characterization of Ti-6Al-4V Parts from Electron Beam Additive Manufacturing. ASME 2014 International Mechanical Engineering Congress and Exposition, Canada, November 14-20, 2014

[47] D.J. Kotecki, T.A. Siewert, WRC-1992 constitution diagram for stainless steel weld metals: a modification of the WRC-1988 diagram, Weld. J. 71(5) (1992) 171178

[48] S. Kou, Solidification and liquation cracking issues in welding. JOM 55(6) (2003) 37-42

[49] http://www.twi-global.com/ 
Fig. 1. Schematic of the tubular butt joint configuration with a built-in backing bar

Fig. 2. Setup for the (a) laser-based welding and (b) induction heating system

Fig. 3. Schematic setups for the (a) laser welding assisted with a filler wire and (b) hybrid laserGMA welding

Fig. 4. Schematic of the on-line monitoring system with a high-speed CCD camera and a spectrometer

Fig. 5. Schematic cross-section of the tubular butt joint configuration with a built-in backing bar

Fig. 6. The schematic view of the area of the joint cross-section

Fig. 7. The weld configurations and the weld cross-sections corresponding to Table 2

Fig. 8. The relationship among number of reflections $\left(n_{r}\right)$, corresponding absorption coefficient, and the groove angle [29].

Fig. 9. The high-speed CCD camera captured images about the plasmas plume generated during the (a) laser welding, (b) GMA welding, and (c) hybrid laser-GMA welding of 17-4 PH martensitic SS

Fig. 10. The plasma emission spectrum intensities captured by spectrometer generated during the (a) laser welding and (b) hybrid laser-GMA welding

Fig. 11. The plasma and plume captured by a high-speed CCD camera under different shielding gases

Fig. 12. The spectrum intensities captured by spectrometer during laser welding under different shielding gases

Fig. 13. Different kind of pores presented in the longitudinal cross-sections of the SS welds

Fig. 14. Longitudinal cross-sectional view of the weld obtained under various welding speed of (a) 5 $\mathrm{mm} / \mathrm{s}$, (b) $10 \mathrm{~mm} / \mathrm{s}$, and (c) $30 \mathrm{~mm} / \mathrm{s}$ with a laser power of $9.9 \mathrm{~kW}$, arc current of $235 \mathrm{~A}$, argon was used as shielding gas with a flow rate of $991 \mathrm{LPH}$

Fig. 15. Schematic view of the effects of fluid flows on bubbles formation during laser welding at various speeds: (a) low welding speed, (b) medium welding speed, and (c) high welding speed [39].

Fig. 16. Longitudinal cross-section of the weld obtained under shielding gas of (a) argon and (b) nitrogen with a laser power of $9.9 \mathrm{~kW}$, welding speed of $10 \mathrm{~mm} / \mathrm{s}$, arc current of $235 \mathrm{~A}$, shielding gas flow rate of $991 \mathrm{LPH}$

Fig. 17. Sequence of phase transformation for the PH martensitic SS cooling [9]

Fig. 18. Weld was acquired by the hybrid laser-GMA welding without preheating

Fig. 19. Microstructure of the (a) upper part, and (b) lower part of the weld as shown in Fig. 19 
Fig. 20. Weld was acquired by the hybrid laser-GMA welding under preheating temperature of $300{ }^{\circ} \mathrm{C}$

Fig. 21. Microstructure of the (a) upper part, and (b) lower part of the weld which was acquired under preheating temperature of $300^{\circ} \mathrm{C}$

Fig. 22. Schematic of the two-pass laser-based welding of 17-4 PH martensitic SS for (a) Procedure No. 1 and (b) Procedure No. 2

Fig. 23. The top, longitudinal, and cross-sectional views of the joints obtained by the two-pass laserbased welding of 17-4 PH martensitic SS for welds obtained by: (a) Procedure No. 1 and (b)

Procedure No. 2

Fig. 24. The micro-hardness distribution profiles at the cross-section of the laser-based welded of 174 PH martensitic SS for welds obtained by: (a) Procedure No. 1 and (b) Procedure No. 2 


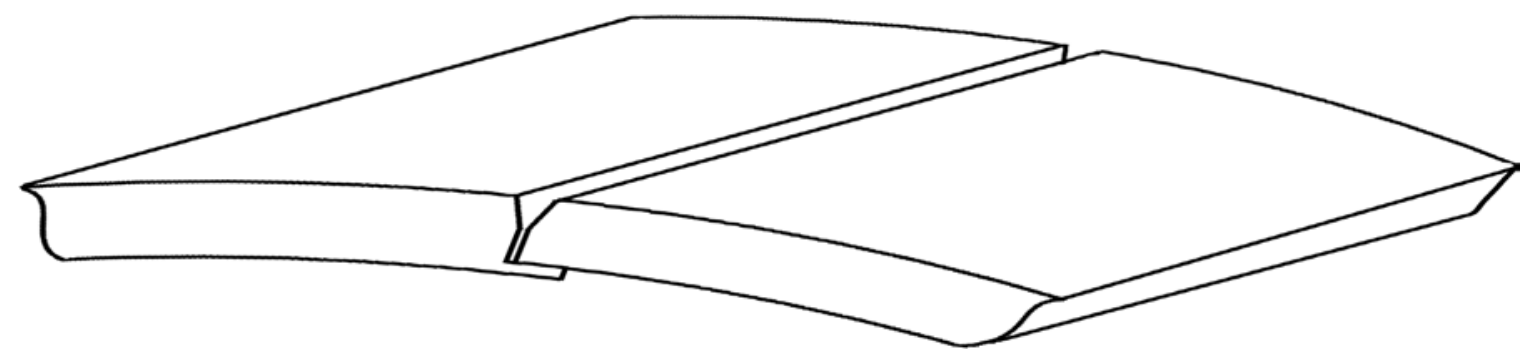

Fig. 1. Schematic of the tubular butt joint configuration with a built-in backing bar 


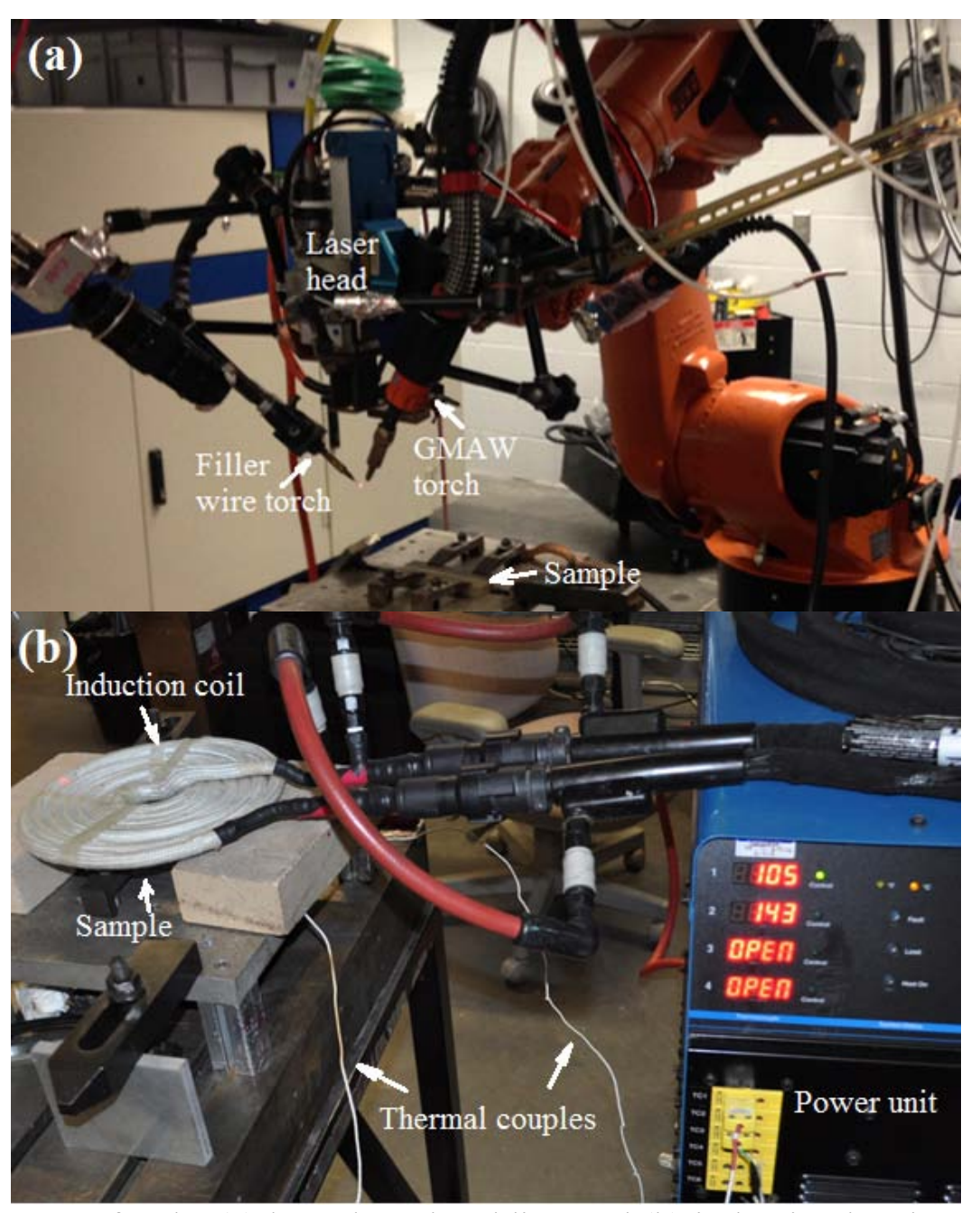

Fig. 2. Setup for the (a) laser-based welding and (b) induction heating system 
(a)

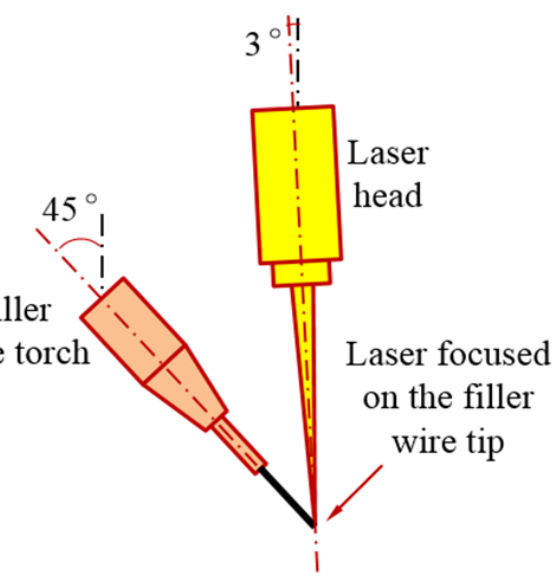

(b)

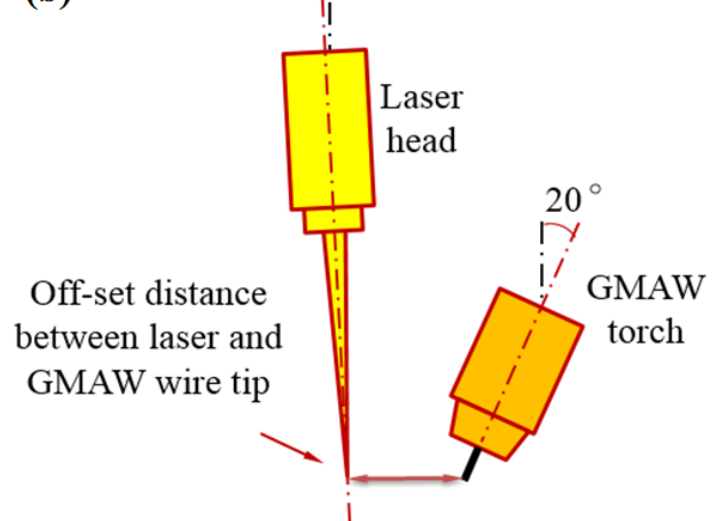

Fig. 3. Schematic setups for the (a) laser welding assisted with a filler wire and (b) hybrid laserGMA welding 


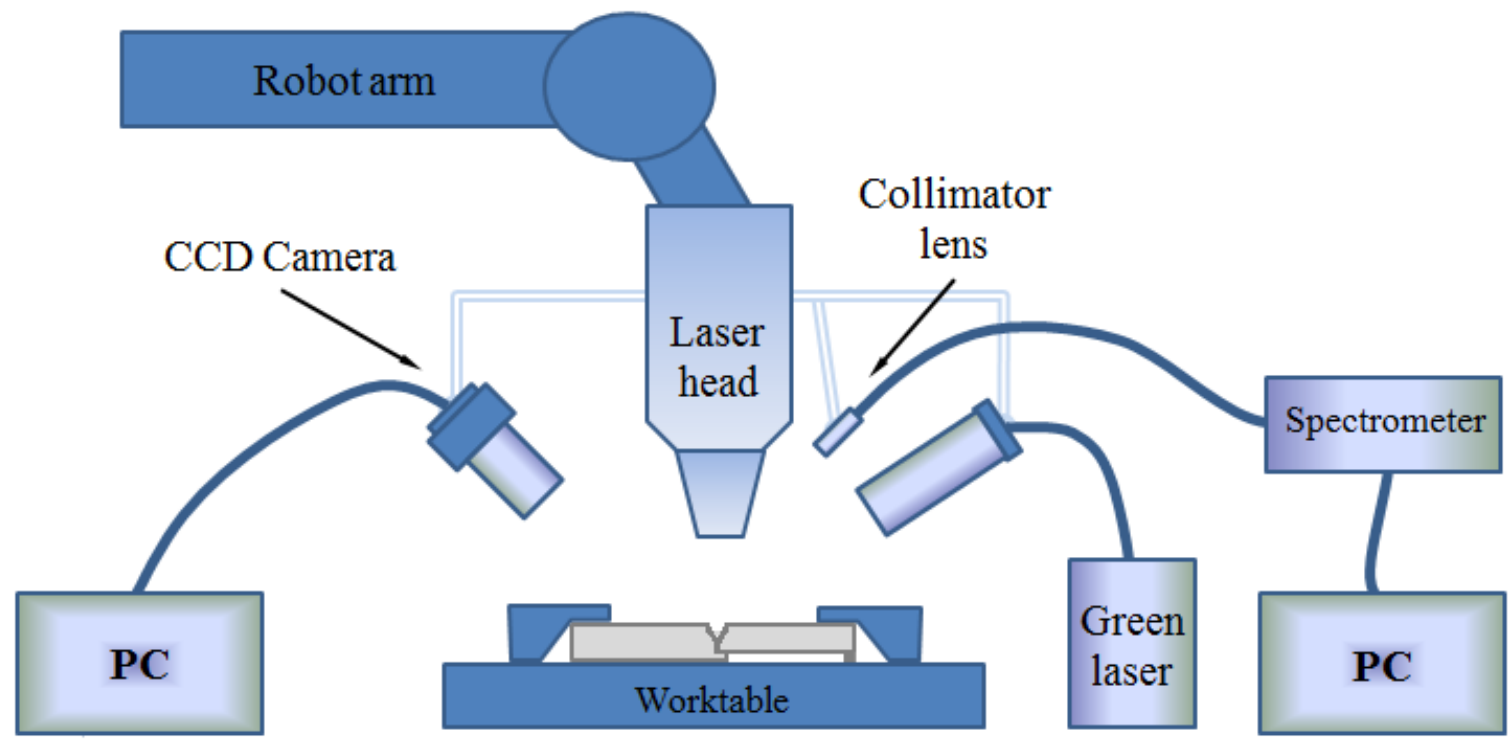

Fig. 4. Schematic of the on-line monitoring system with a high-speed CCD camera and a spectrometer 


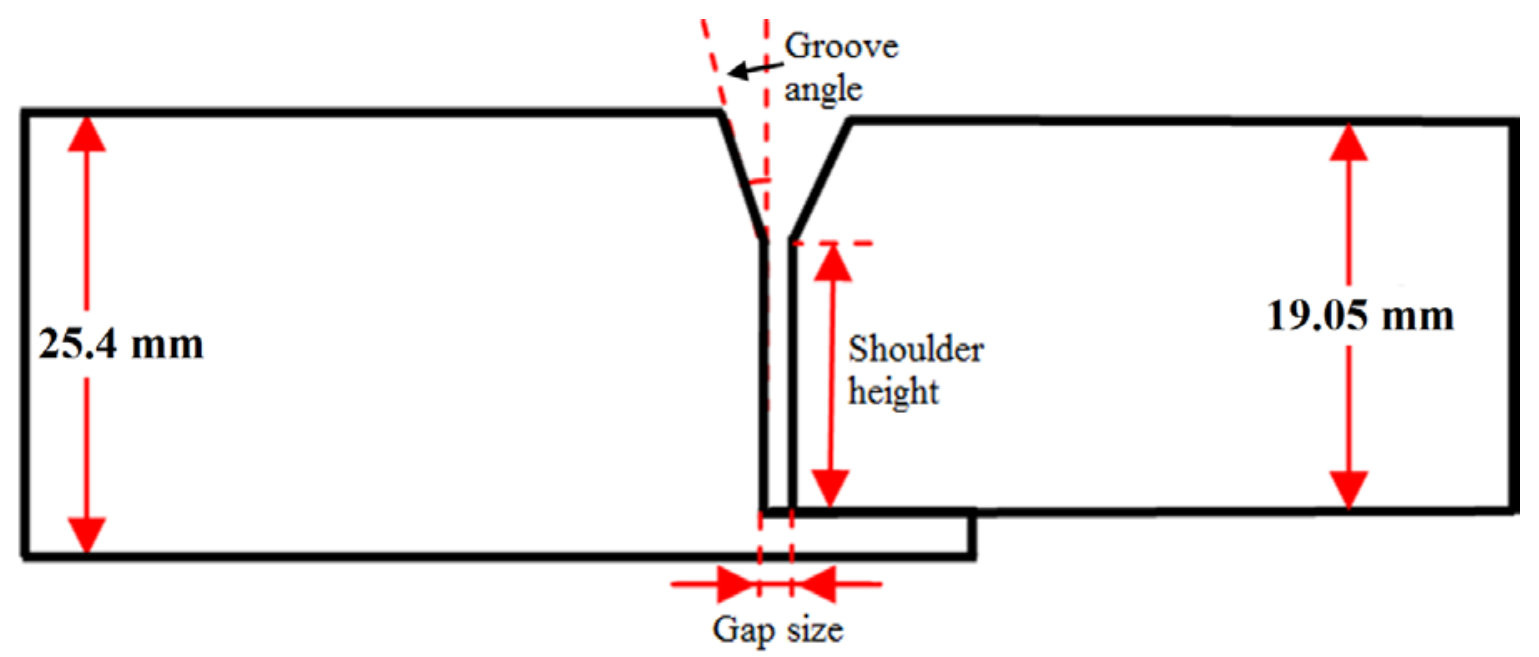

Fig. 5. Schematic cross-section of the tubular butt joint configuration with a built-in backing bar 


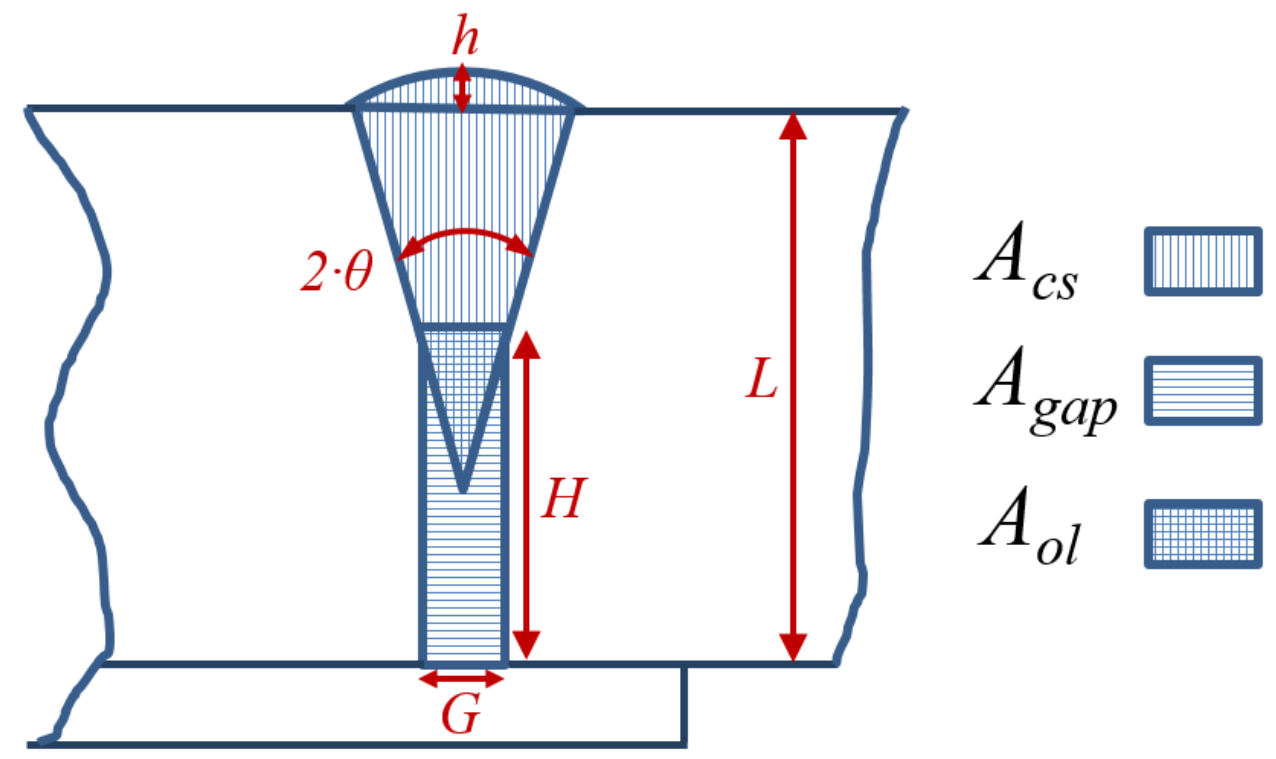

Fig. 6. The schematic view of the area of the joint cross-section 

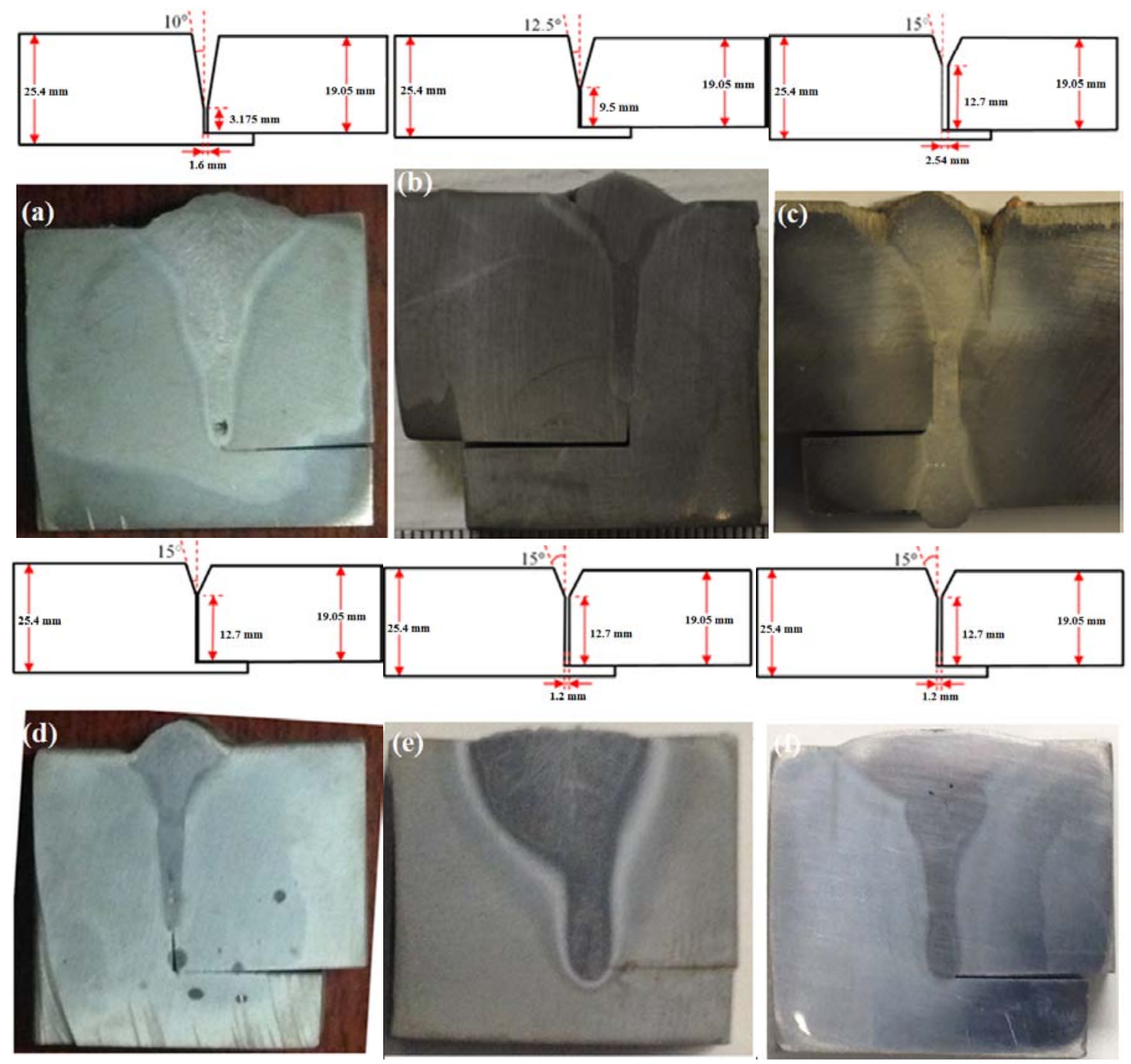

Fig. 7. The weld configurations and the weld cross-sections corresponding to Table 2 


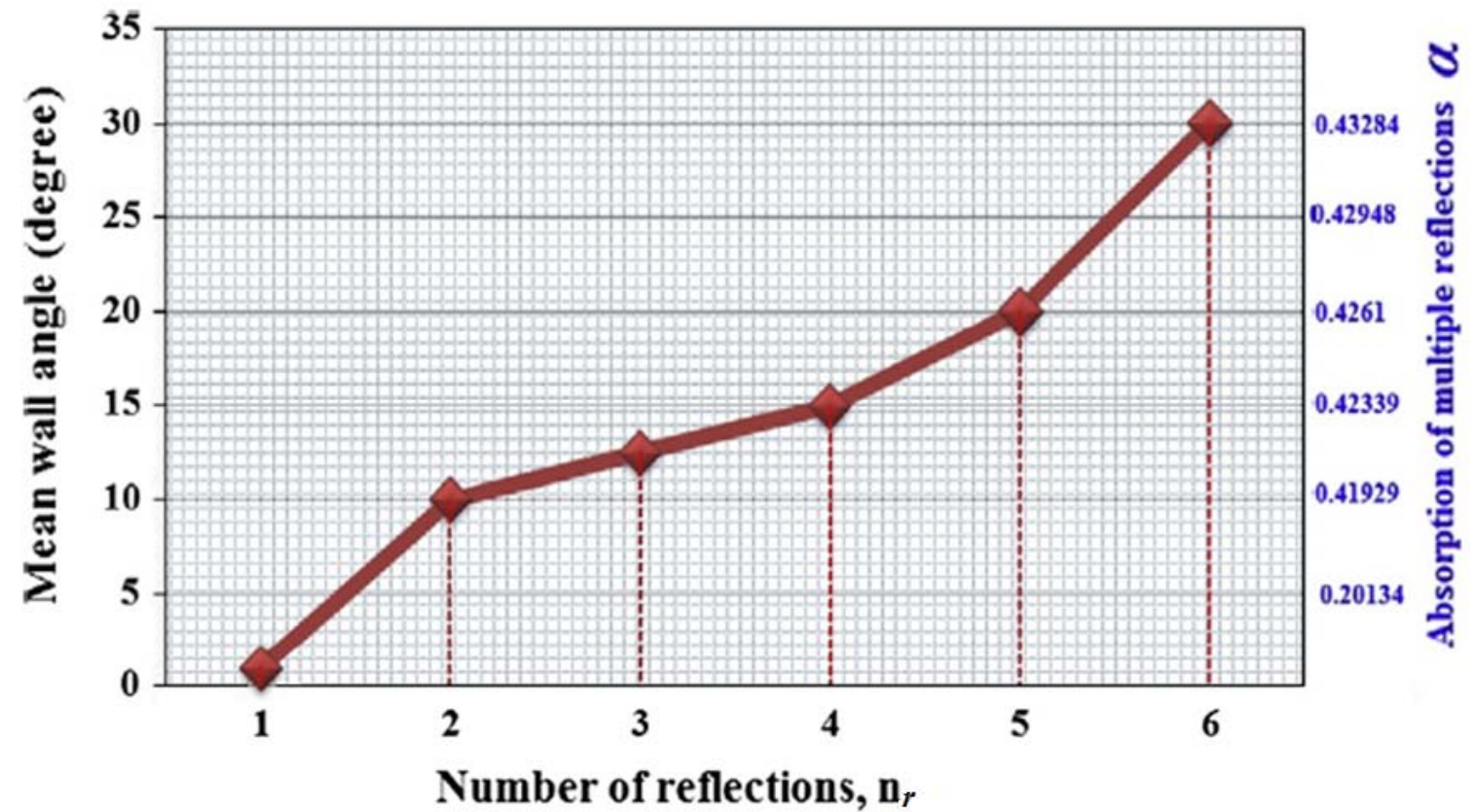

Fig. 8. The relationship among number of reflections $\left(n_{r}\right)$, corresponding absorption coefficient, and the groove angle [29]. 

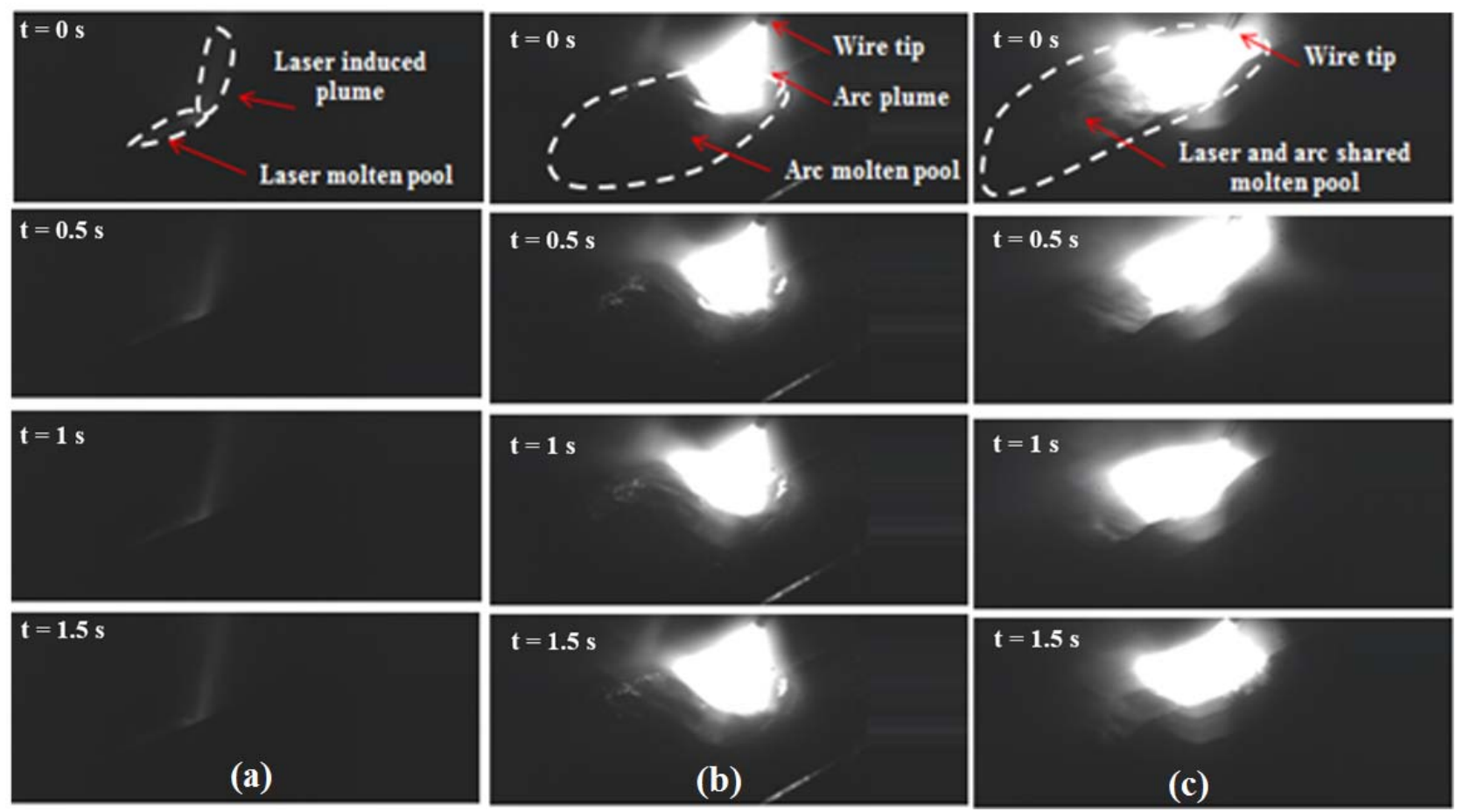

Fig. 9. The high-speed CCD camera captured images about the plasmas plume generated during the (a) laser welding, (b) GMA welding, and (c) hybrid laser-GMA welding of 17-4 PH martensitic SS 

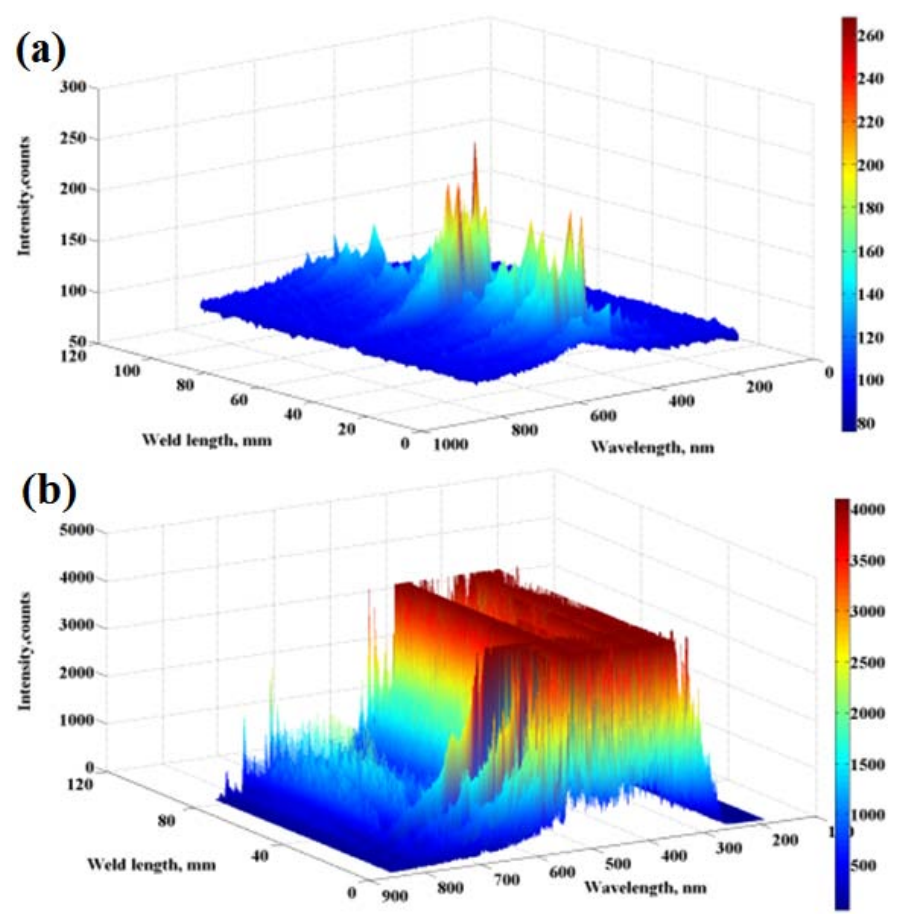

Fig. 10. The plasma emission spectrum intensities captured by spectrometer generated during the (a) laser welding and (b) hybrid laser-GMA welding 


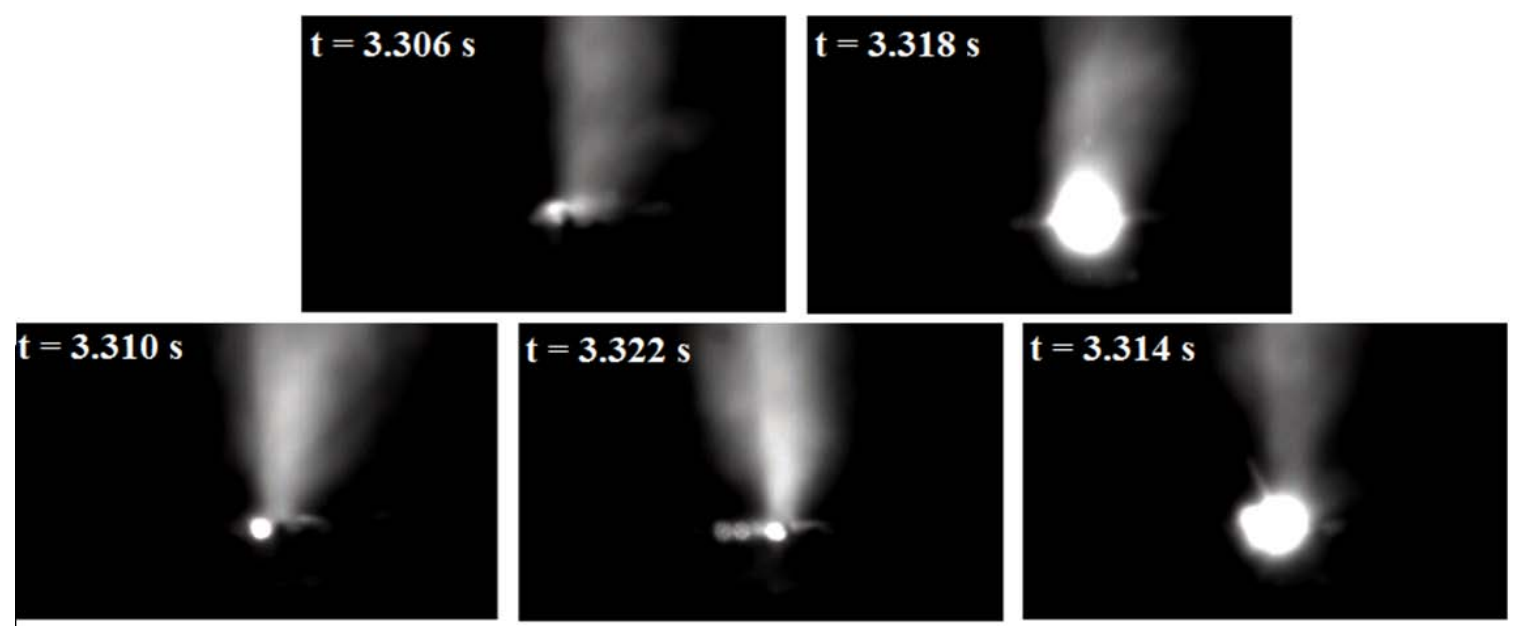

(a) using the nitrogen as shielding gas

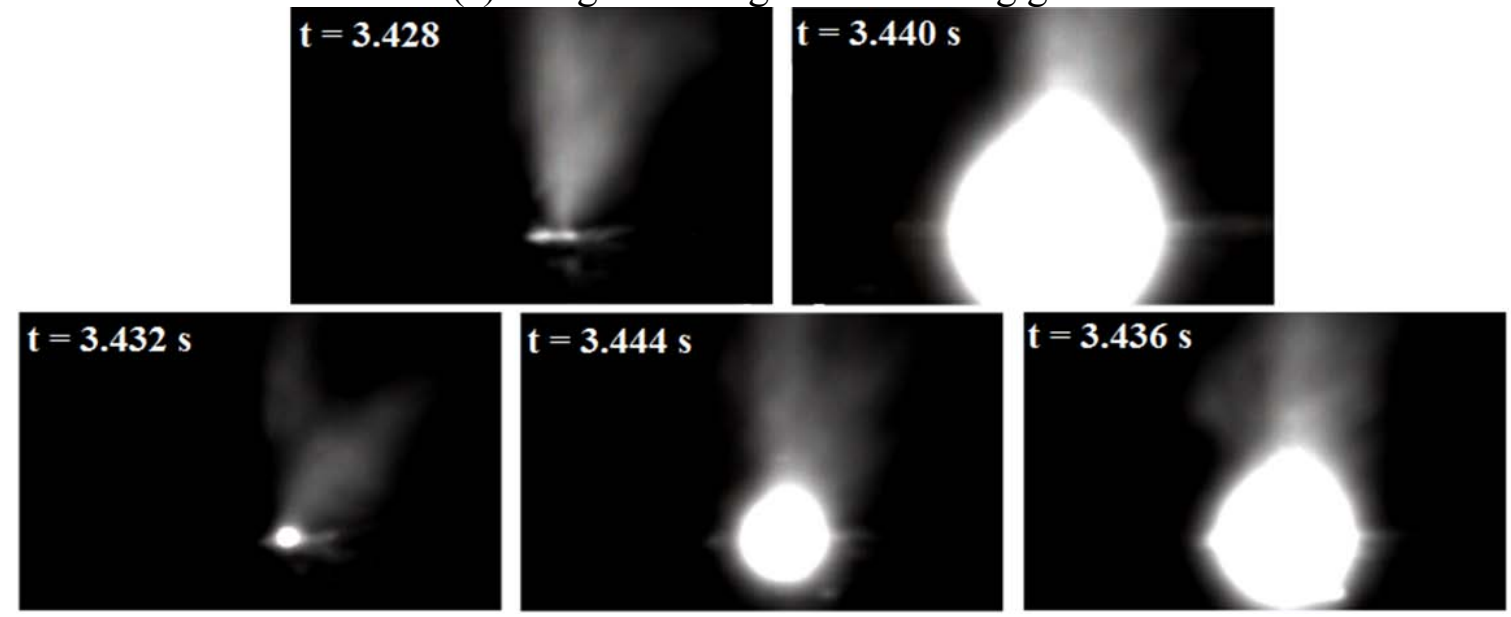

(b) using the argon as shielding gas

Fig. 11. The plasma and plume captured by a high-speed CCD camera under different shielding gases 


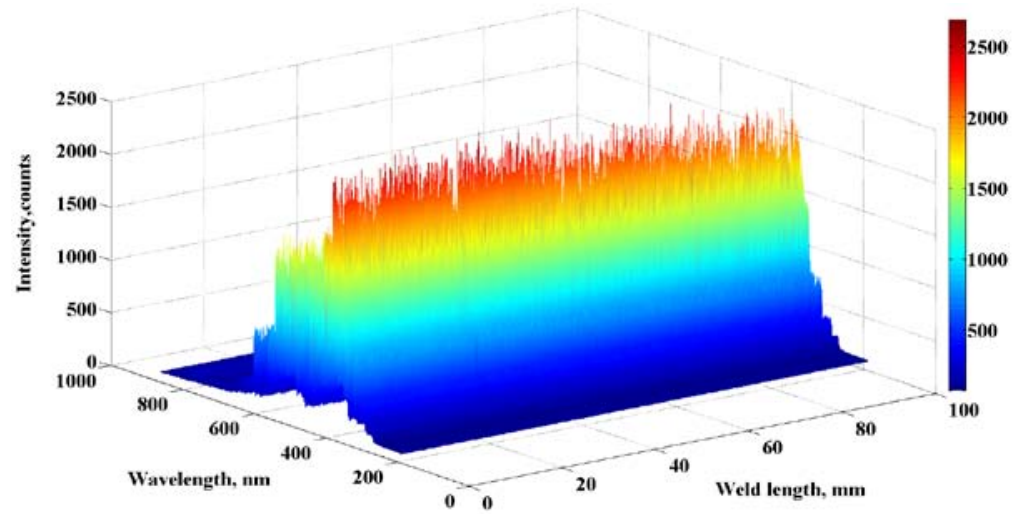

(a) using the nitrogen as shielding gas

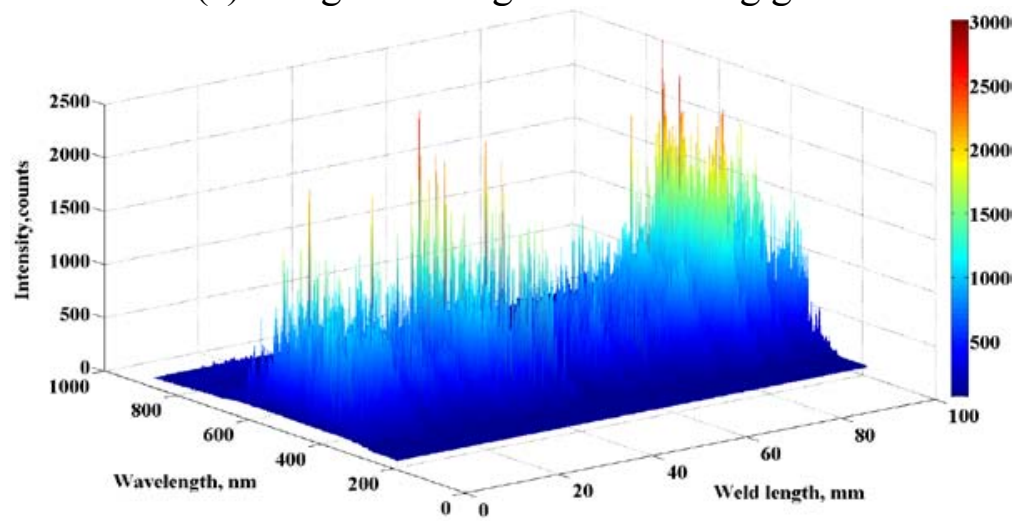

(b) using the argon as shielding gas

Fig. 12. The spectrum intensities captured by spectrometer during laser welding under different shielding gases 


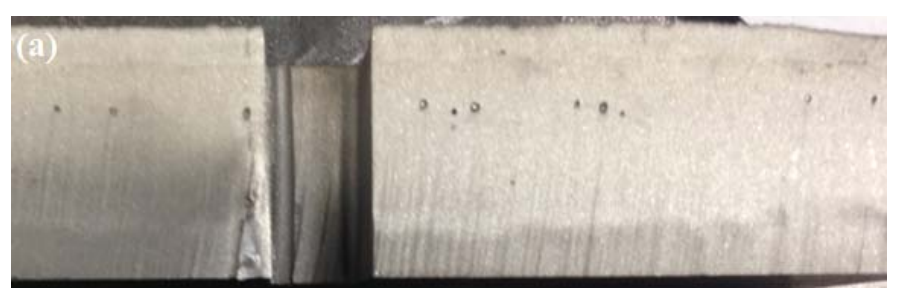

(a) pores induced by the shielding gases

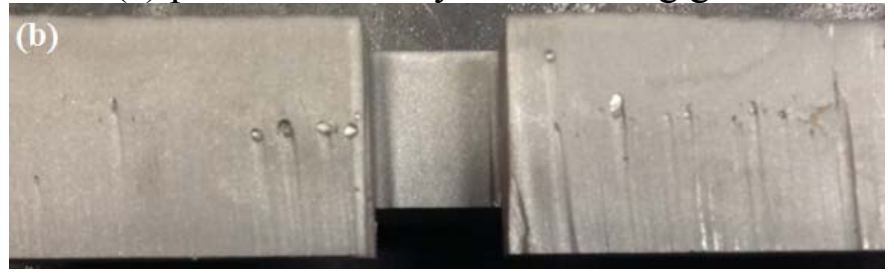

(b) pores induced by the collapsed keyhole

Fig. 13. Different kind of pores presented in the longitudinal cross-sections of the SS welds 


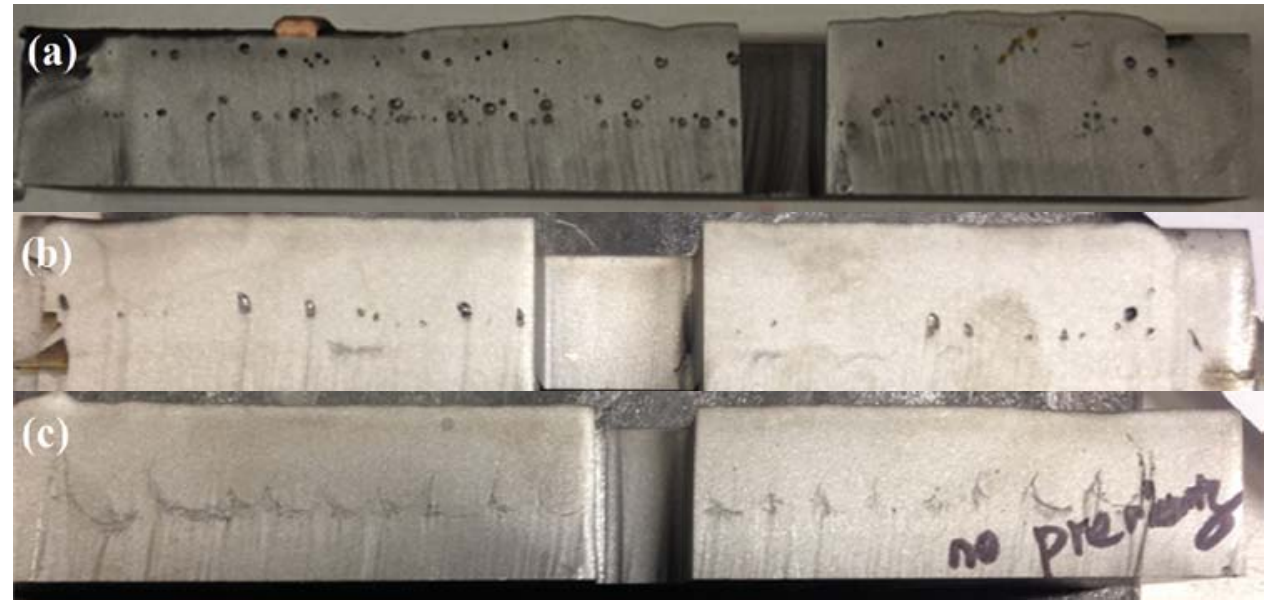

Fig. 14. Longitudinal cross-sectional view of the weld obtained under various welding speed of (a) 5 $\mathrm{mm} / \mathrm{s}$, (b) $10 \mathrm{~mm} / \mathrm{s}$, and (c) $30 \mathrm{~mm} / \mathrm{s}$ with a laser power of $9.9 \mathrm{~kW}$, arc current of $235 \mathrm{~A}$, argon was used as shielding gas with a flow rate of $991 \mathrm{LPH}$ 


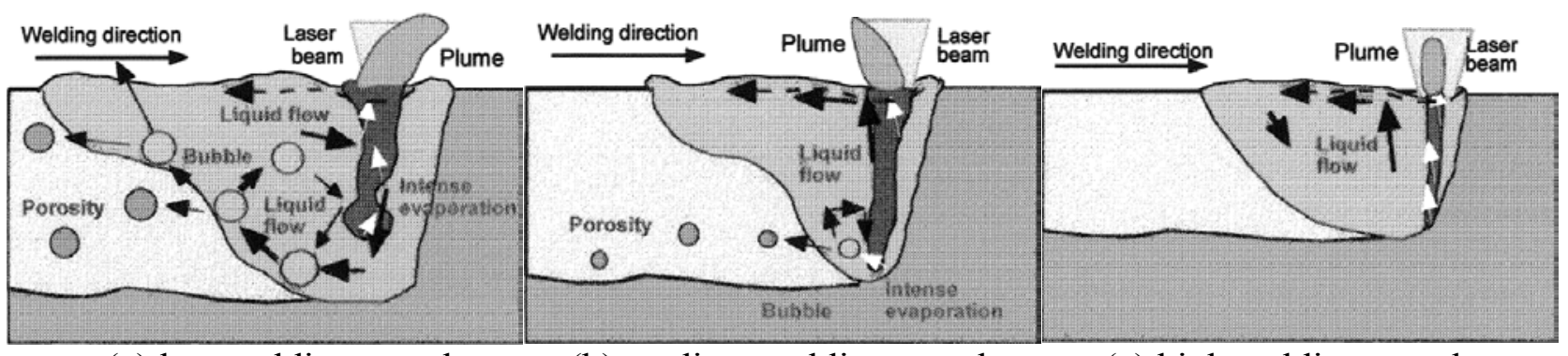

(a) low welding speed

(b) medium welding speed

(c) high welding speed

Fig. 15. Schematic view of the effects of fluid flows on bubbles formation during laser welding at various speeds: (a) low welding speed, (b) medium welding speed, and (c) high welding speed [39]. 


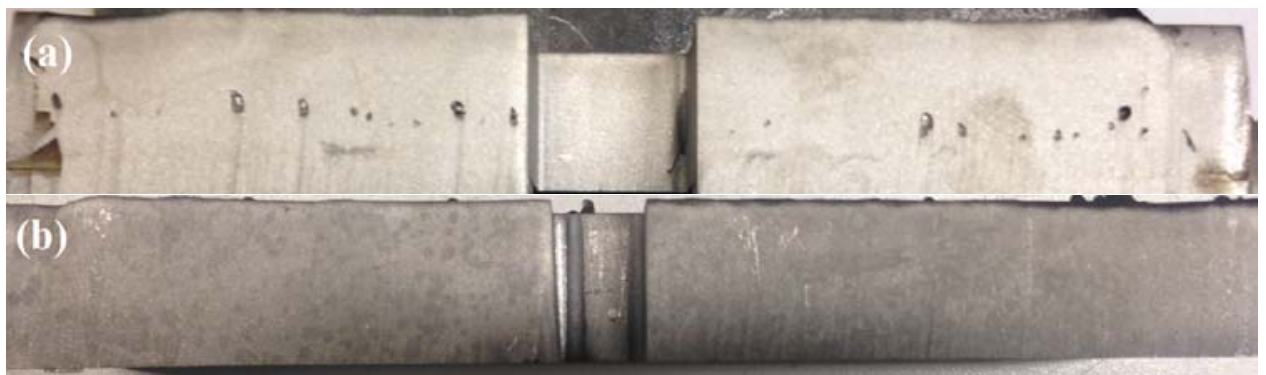

Fig. 16. Longitudinal cross-section of the weld obtained under shielding gas of (a) argon and (b) nitrogen with a laser power of $9.9 \mathrm{~kW}$, welding speed of $10 \mathrm{~mm} / \mathrm{s}$, arc current of $235 \mathrm{~A}$, shielding gas flow rate of $991 \mathrm{LPH}$ 


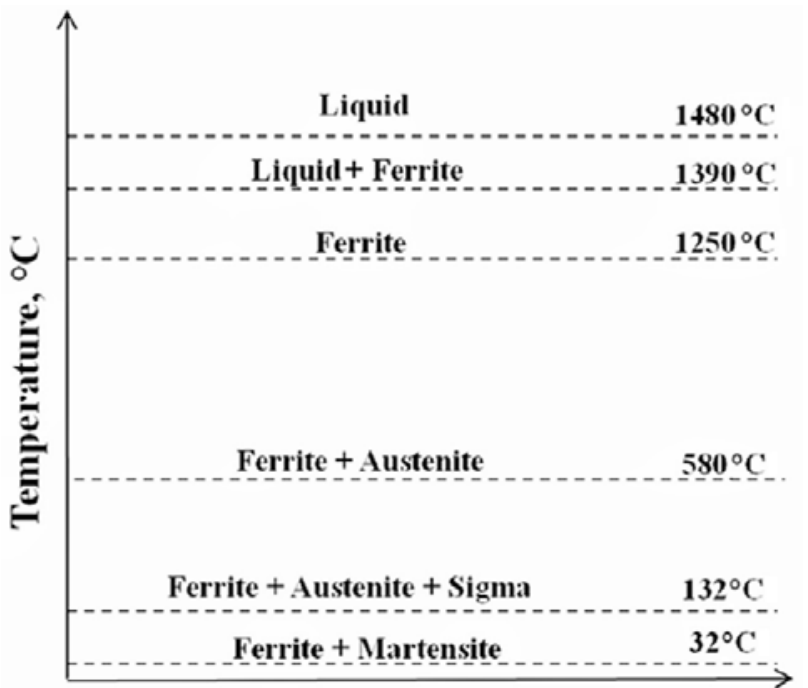

Fig. 17. Sequence of phase transformation for the PH martensitic SS cooling [9] 


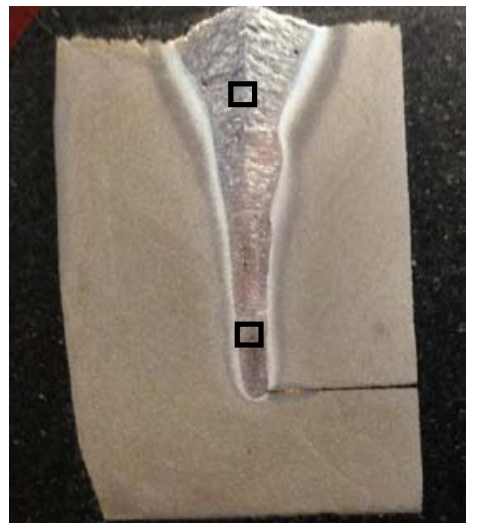

Fig. 18. Weld was acquired by the hybrid laser-GMA welding without preheating 

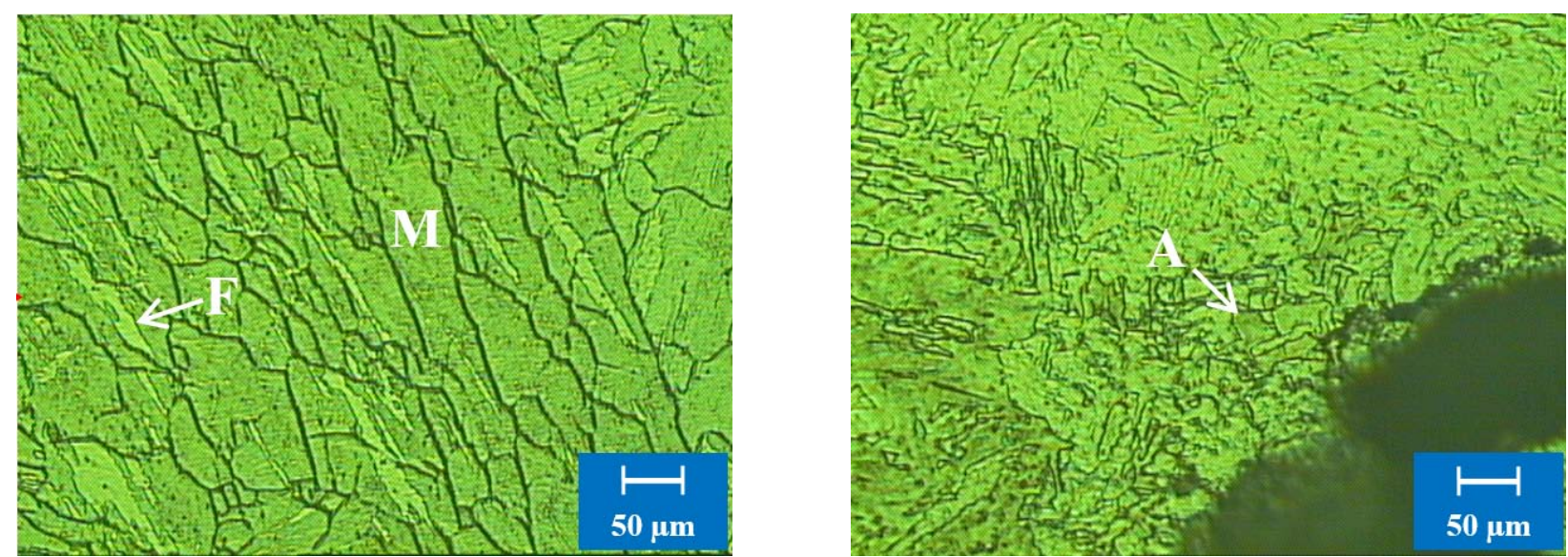

Fig. 19. Microstructure of the (a) upper part, and (b) lower part of the weld as shown in Fig. 19 


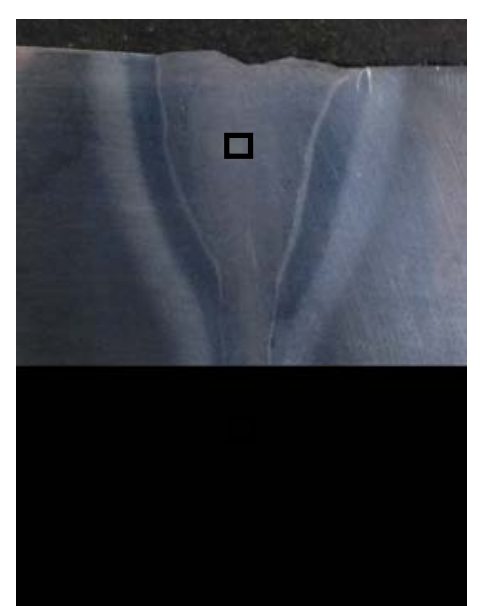

Fig. 20. Weld was acquired by the hybrid laser-GMA welding under preheating temperature of $300{ }^{\circ} \mathrm{C}$ 

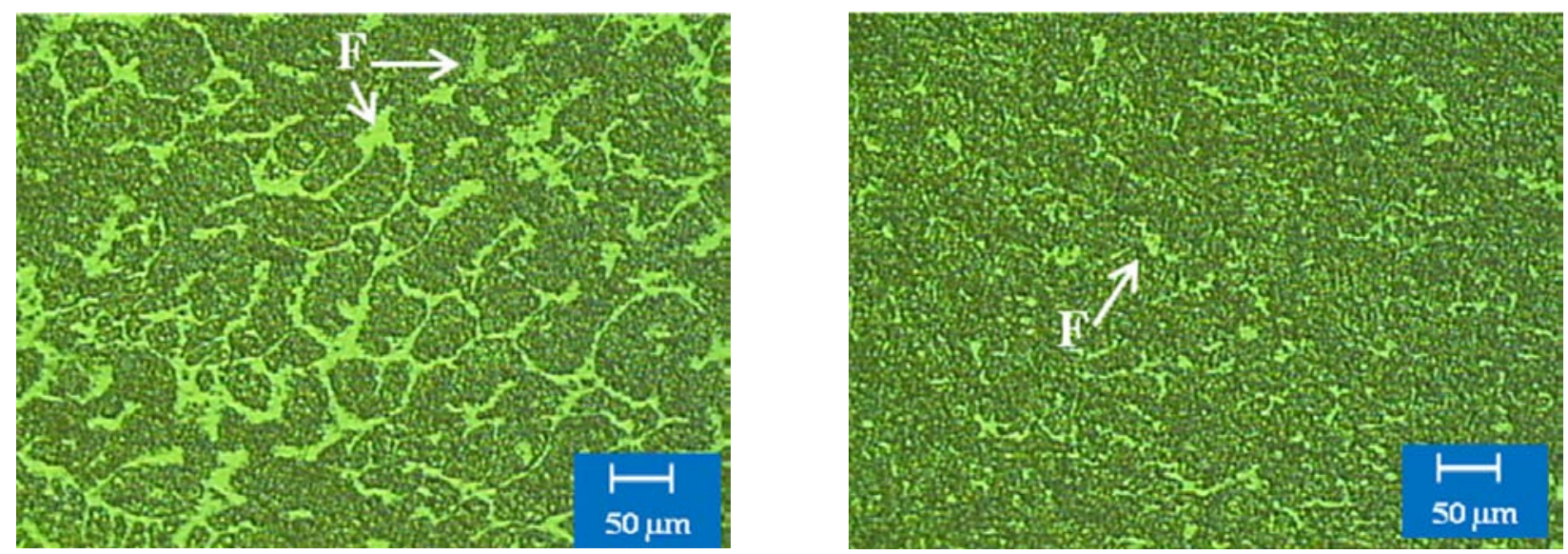

Fig. 21. Microstructure of the (a) upper part, and (b) lower part of the weld which was acquired under preheating temperature of $300^{\circ} \mathrm{C}$ 

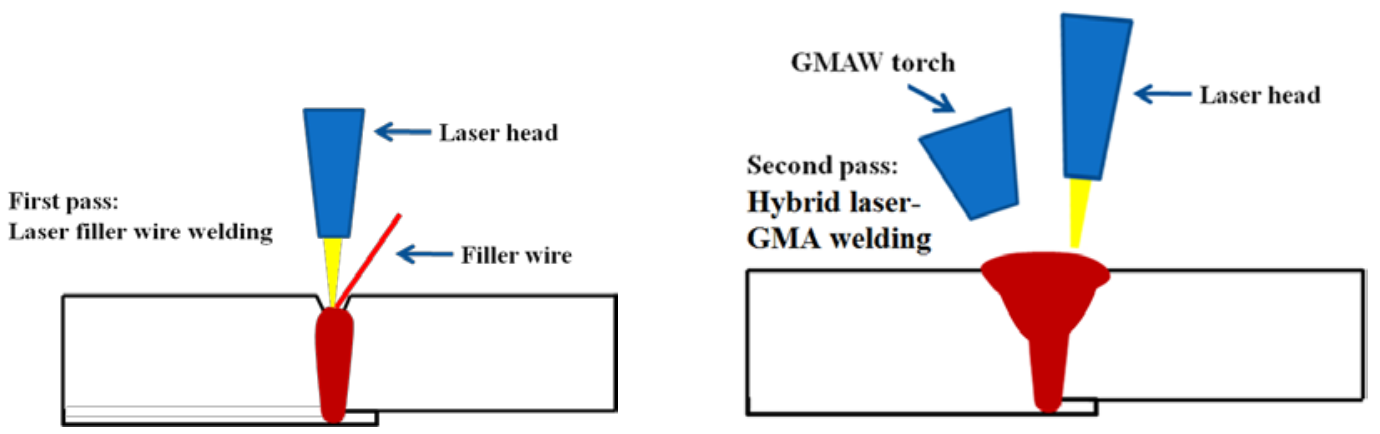

(a) Procedure No. 1

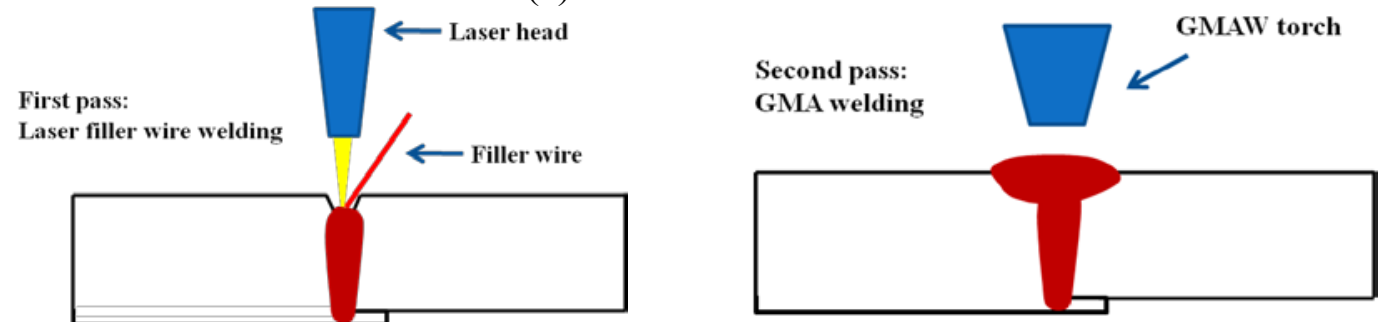

(b) Procedure No. 2

Fig. 22. Schematic of the two-pass laser-based welding of 17-4 PH martensitic SS for (a) Procedure No. 1 and (b) Procedure No. 2 


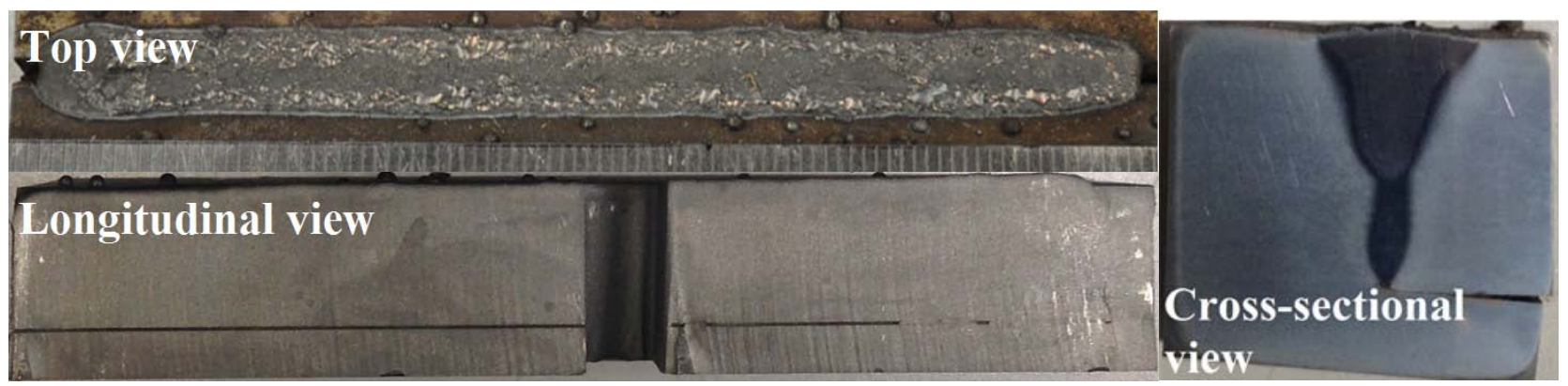

(a) Procedure No. 1

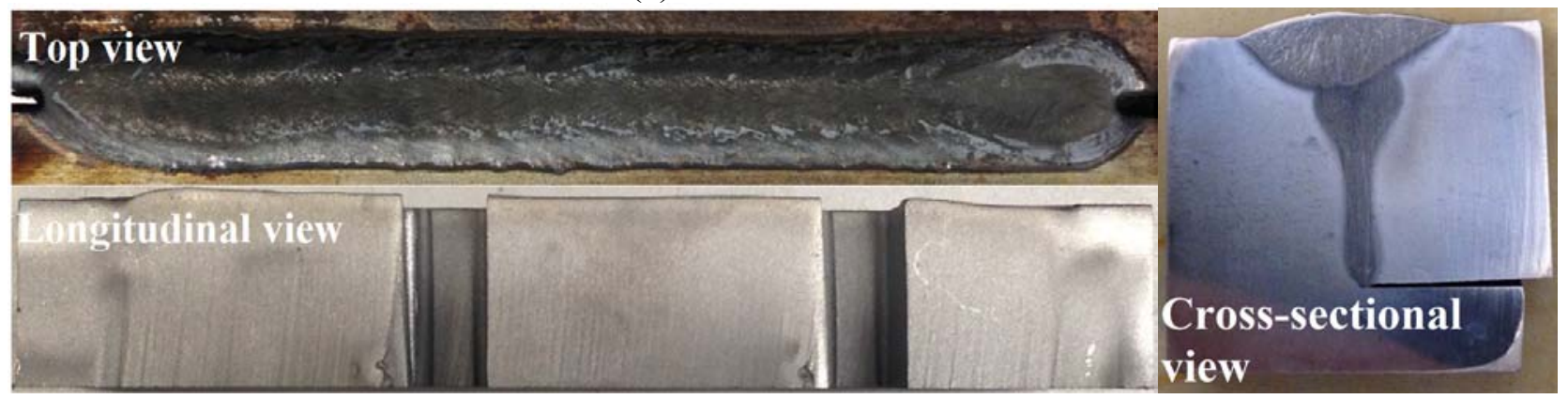

(b) Procedure No. 2

Fig. 23. The top, longitudinal, and cross-sectional views of the joints obtained by the two-pass laser-based welding of 17-4 PH martensitic SS for welds obtained by: (a) Procedure No. 1 and (b) Procedure No. 2 

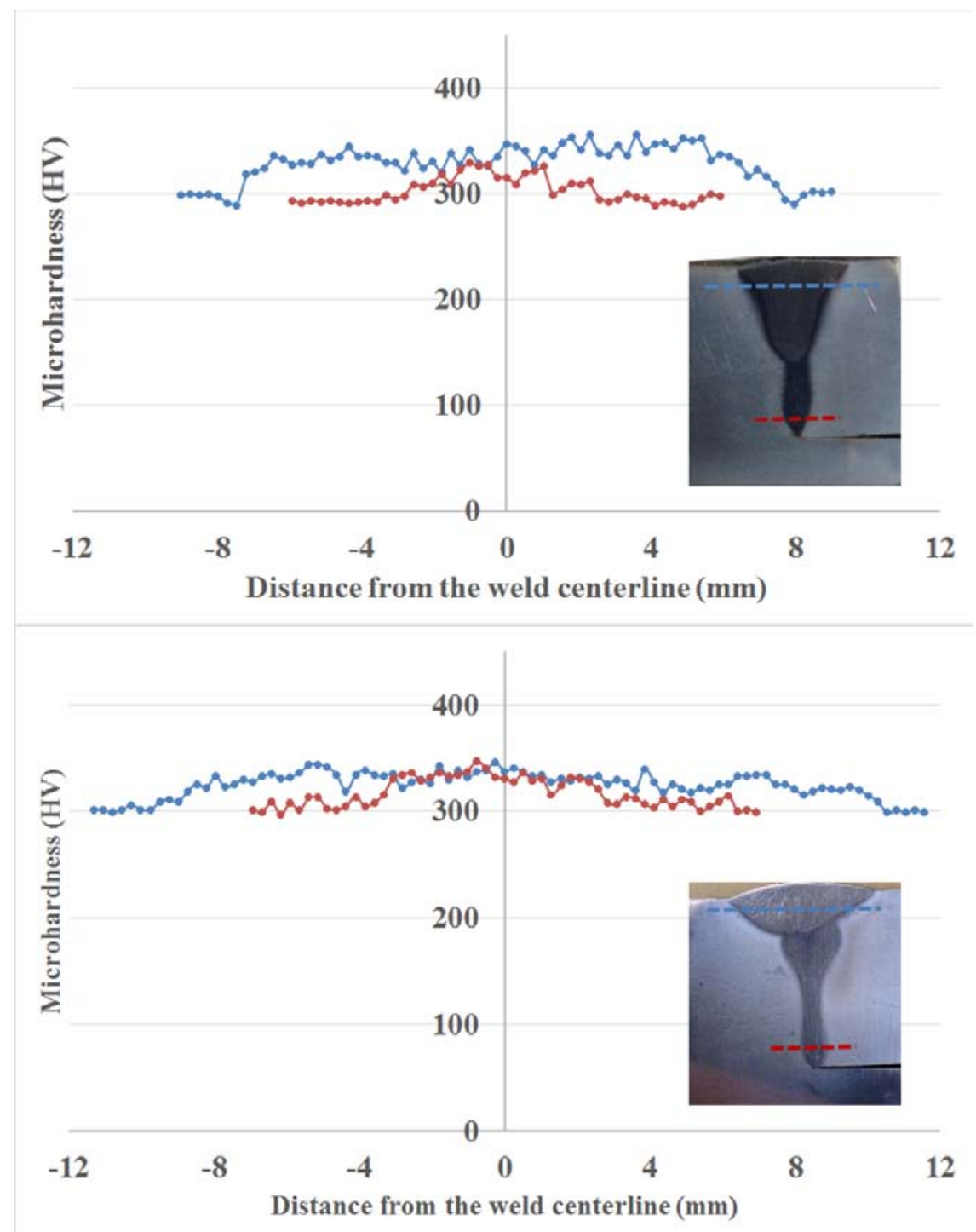

Fig. 24. The micro-hardness distribution profiles at the cross-section of the laser-based welded of 17-4 PH martensitic SS for welds obtained by: (a) Procedure No. 1 and (b) Procedure No. 2 
Table 1 Chemical composition of 17-4 PH martensitic SS and ER 630 filler wire, wt\% [9]

Table 2 Order of experimental trials with corresponding results

Table 3. The optimum laser-based welding parameter

Table 1 Chemical composition of 17-4 PH martensitic SS and ER 630 filler wire, wt $\%$ [9]

\begin{tabular}{c|ccccccccccc} 
Material & $\mathrm{C}$ & $\mathrm{Mn}$ & $\mathrm{S}$ & $\mathrm{P}$ & $\mathrm{Si}$ & $\mathrm{Cr}$ & $\mathrm{Ni}$ & $\mathrm{Mo}$ & $\mathrm{Cu}$ & $\mathrm{Nb}+\mathrm{V}$ & $\mathrm{Fe}$ \\
\hline $\begin{array}{c}\text { 17-4 PH } \\
\mathrm{SS}\end{array}$ & 0.01 & 0.86 & 0.007 & 0.021 & 0.8 & 15.74 & 3.96 & 0.06 & 2.74 & 0.3 & Balance \\
\hline $\begin{array}{c}\text { ER 630 } \\
\text { filler wire }\end{array}$ & 0.032 & 0.54 & 0.01 & 0.021 & 0.37 & 16.2 & 4.59 & 0.68 & 3.9 & 0.27 & Balance \\
\hline
\end{tabular}


Table 2 Order of experimental trials with corresponding results

\begin{tabular}{|c|c|c|c|c|c|c|c|}
\hline & \multirow{2}{*}{ Welding parameters } & \multicolumn{3}{|c|}{ Groove geometry } & \multirow{2}{*}{$\begin{array}{l}\text { Heat input } \\
(\mathrm{kJ} / \mathrm{mm})\end{array}$} & \multirow{2}{*}{$\begin{array}{l}\text { volume } \\
\left(\mathrm{mm}^{3}\right)\end{array}$} & \multirow{2}{*}{ Weld Results } \\
\hline & & $\theta\left(^{\circ}\right)$ & $\mathrm{H}(\mathrm{mm})$ & $\mathrm{G}(\mathrm{mm})$ & & & \\
\hline \multirow[t]{2}{*}{$\mathrm{a}$} & $\begin{array}{l}\text { Hybrid laser/GMA welding: laser power of } 9 \\
\mathrm{~kW} \text {, welding speed of } 20 \mathrm{~mm} / \mathrm{s} \text {, wire feed rate } \\
\text { of } 300 \mathrm{~mm} / \mathrm{s} \text {, arc current of } 290 \mathrm{~A} \text {. }\end{array}$ & \multirow[t]{2}{*}{10} & \multirow[t]{2}{*}{3} & \multirow[t]{2}{*}{1.6} & 1.008 & \multirow[t]{2}{*}{13489.4} & \multirow[t]{2}{*}{ Porosity presented in the weld } \\
\hline & $\begin{array}{l}\text { GMA welding: welding speed of } 15 \mathrm{~mm} / \mathrm{s} \text {, wire } \\
\text { feed rate of } 250 \mathrm{~mm} / \mathrm{s} \text {, arc current of } 245 \mathrm{~A} \text {. }\end{array}$ & & & & 0.6174 & & \\
\hline \multirow{2}{*}{ b } & $\begin{array}{l}\text { Laser welding: laser power of } 9.9 \mathrm{~kW} \text {, welding } \\
\text { speed of } 20 \mathrm{~mm} / \mathrm{s} \text {. }\end{array}$ & \multirow{2}{*}{12.5} & \multirow{2}{*}{9} & \multirow{2}{*}{ no gap } & 0.495 & \multirow{2}{*}{5427.84} & \multirow{2}{*}{$\begin{array}{l}\text { Lack of penetration, and cracks } \\
\text { were observed in the weld }\end{array}$} \\
\hline & $\begin{array}{l}\text { GMA welding: welding speed of } 15 \mathrm{~mm} / \mathrm{s} \text {, wire } \\
\text { feed rate of } 250 \mathrm{~mm} / \mathrm{s} \text {, arc current of } 245 \mathrm{~A} \text {. }\end{array}$ & & & & 0.6174 & & \\
\hline \multirow[t]{2}{*}{ c } & $\begin{array}{l}\text { Hybrid laser/GMA welding: laser power of } 9 \\
\mathrm{~kW} \text {, welding speed of } 20 \mathrm{~mm} / \mathrm{s} \text {, wire feed rate } \\
\text { of } 250 \mathrm{~mm} / \mathrm{s} \text {, arc current of } 245 \mathrm{~A} \text {. }\end{array}$ & \multirow[t]{2}{*}{15} & \multirow[t]{2}{*}{12.7} & \multirow[t]{2}{*}{2.5} & 0.913 & \multirow[t]{2}{*}{9774.52} & \multirow{2}{*}{$\begin{array}{l}\text { Undercuts, lack of melt on the gap } \\
\text { edge }\end{array}$} \\
\hline & $\begin{array}{l}\text { GMA welding: welding speed of } 15 \mathrm{~mm} / \mathrm{s} \text {, wire } \\
\text { feed rate of } 250 \mathrm{~mm} / \mathrm{s} \text {, arc current of } 245 \mathrm{~A} \text {. }\end{array}$ & & & & 0.6174 & & \\
\hline \multirow{2}{*}{$\mathrm{d}$} & $\begin{array}{l}\text { Laser welding:laser power of } 9.9 \mathrm{~kW} \text {, welding } \\
\text { speed of } 15 \mathrm{~mm} / \mathrm{s} \text {. }\end{array}$ & \multirow{2}{*}{15} & \multirow{2}{*}{12.7} & \multirow{2}{*}{ no gap } & 0.66 & \multirow{2}{*}{3525.55} & \multirow{2}{*}{$\begin{array}{l}\text { Lack of penetration, and cracks } \\
\text { were observed in the weld }\end{array}$} \\
\hline & $\begin{array}{l}\text { GMA welding: welding speed of } 15 \mathrm{~mm} / \mathrm{s} \text {, wire } \\
\text { feed rate of } 167 \mathrm{~mm} / \mathrm{s} \text {, arc current of } 175 \mathrm{~A} \text {. }\end{array}$ & & & & 0.4142 & & \\
\hline \multirow{2}{*}{ f } & $\begin{array}{l}\text { Laser welding assistant with filler wire: laser } \\
\text { power of } 9 \mathrm{~kW} \text {, welding speed of } 10 \mathrm{~mm} / \mathrm{s} \text {, wire } \\
\text { feed rate of } 120 \mathrm{~mm} / \mathrm{s} \text {. }\end{array}$ & \multirow{2}{*}{15} & \multirow{2}{*}{12.7} & \multirow{2}{*}{1.2} & 0.9 & \multirow{2}{*}{5456.81} & \multirow{2}{*}{$\begin{array}{l}\text { Cracks were observed in the } \\
\text { lower part of the weld }\end{array}$} \\
\hline & $\begin{array}{l}\text { Hybrid GMA welding: laser power of } 4 \mathrm{~kW} \text {, } \\
\text { welding speed of } 10 \mathrm{~mm} / \mathrm{s} \text {, wire feed rate of } 200 \\
\mathrm{~mm} / \mathrm{s} \text {, arc current of } 225 \mathrm{~A} \text {. }\end{array}$ & & & & 1.221 & & \\
\hline \multirow[t]{2}{*}{ g } & $\begin{array}{l}\text { Laser welding assistant with filler wire: laser } \\
\text { power of } 9.9 \mathrm{~kW} \text {, welding speed of } 10 \mathrm{~mm} / \mathrm{s} \text {, } \\
\text { wire feed rate of } 120 \mathrm{~mm} / \mathrm{s} \text {. }\end{array}$ & \multirow[t]{2}{*}{15} & \multirow[t]{2}{*}{12.7} & 1.2 & 0.99 & 5456.81 & Cracks and porosity were found in \\
\hline & $\begin{array}{l}\text { GMA welding: welding speed of } 6 \mathrm{~mm} / \mathrm{s} \text {, wire } \\
\text { feed rate of } 250 \mathrm{~mm} / \mathrm{s} \text {, arc current of } 245 \mathrm{~A} \text {. }\end{array}$ & & & & 1.544 & & \\
\hline
\end{tabular}


Table 3. The optimum laser-based welding parameter

\begin{tabular}{|c|c|c|c|c|c|c|c|c|c|c|}
\hline \multicolumn{2}{|c|}{ Procedure } & $\begin{array}{l}\text { Welding } \\
\text { procedure }\end{array}$ & $\begin{array}{l}\text { Laser } \\
\text { power } \\
(\mathrm{kW})\end{array}$ & $\begin{array}{l}\text { Welding } \\
\text { speed } \\
(\mathrm{mm} / \mathrm{s})\end{array}$ & $\begin{array}{l}\text { Wire } \\
\text { diameter } \\
(\mathrm{mm})\end{array}$ & $\begin{array}{c}\text { Wire } \\
\text { feed rate } \\
(\mathrm{mm} / \mathrm{s})\end{array}$ & $\begin{array}{l}\text { Arc } \\
\text { current } \\
\text { (A) }\end{array}$ & $\begin{array}{l}\text { Shielding } \\
\text { gas }\end{array}$ & $\begin{array}{l}\text { Gas flow } \\
\text { rate }(\mathrm{LPH})\end{array}$ & $\begin{array}{c}\text { Preheating } \\
\text { temperature } \\
\left({ }^{\circ} \mathrm{C}\right)\end{array}$ \\
\hline \multirow{2}{*}{ No. 1} & $1^{\mathrm{st}}$ pass & $\begin{array}{l}\text { Laser-wire } \\
\text { welding }\end{array}$ & 9 & 10 & 0.9 & 120 & - & Nitrogen & 708 & 300 \\
\hline & $2^{\text {nd }}$ pass & $\begin{array}{l}\text { Hybrid laser- } \\
\text { GMA welding }\end{array}$ & 4 & 10 & 1.2 & 200 & 235 & Nitrogen & 850 & - \\
\hline \multirow{2}{*}{ No. 2} & $1^{\mathrm{st}}$ pass & $\begin{array}{l}\text { Laser-wire } \\
\text { welding }\end{array}$ & 9.9 & 10 & 1.2 & 120 & - & Nitrogen & 708 & 300 \\
\hline & $2^{\text {nd }}$ pass & GMA welding & - & 6 & 0.9 & 250 & 245 & Argon & 850 & - \\
\hline
\end{tabular}



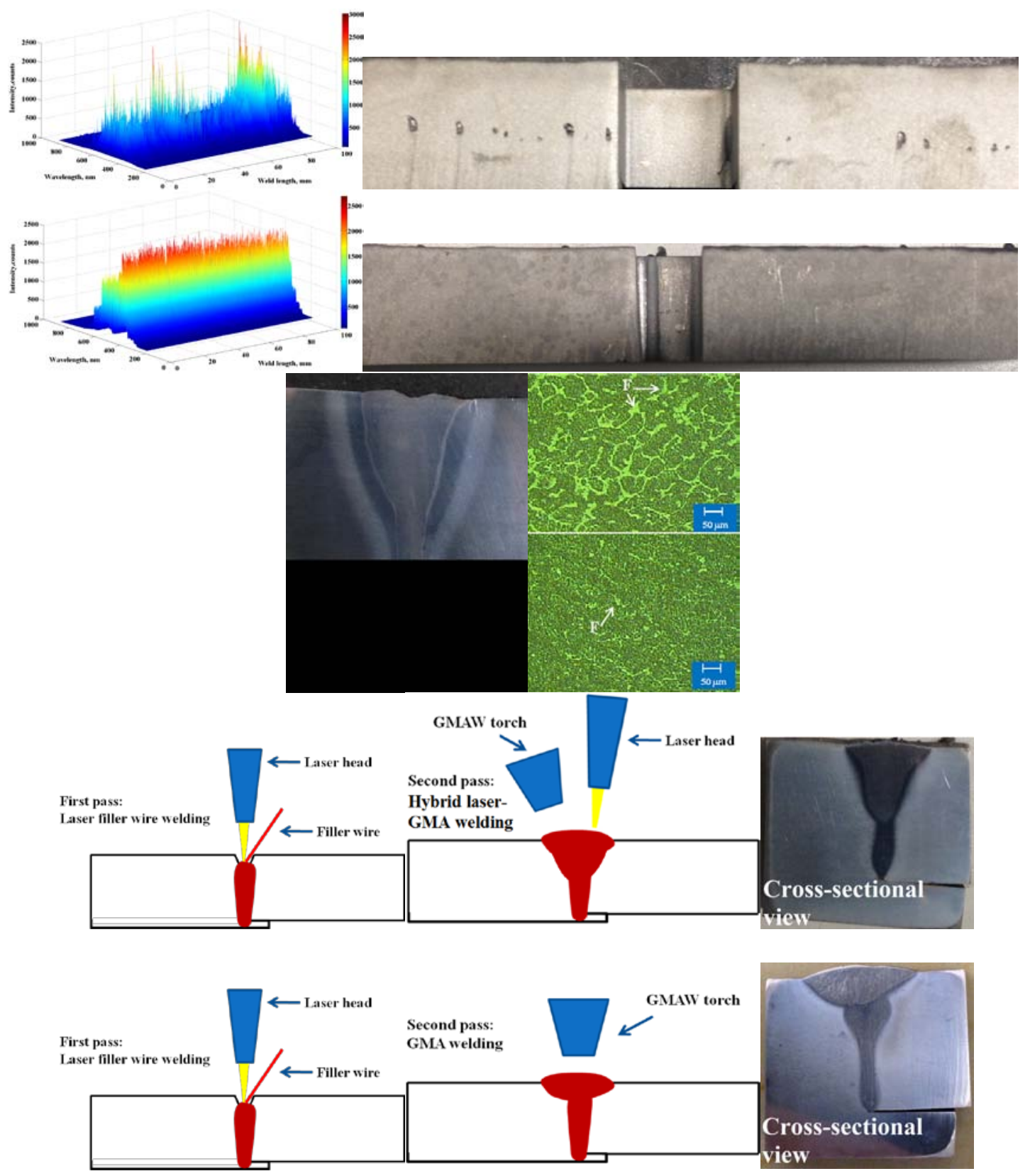

Graphical Abstract 